\title{
Review \\ Binding Materials for MOF Monolith Shaping Processes: A Review towards Real Life Application
}

\author{
Vasileios Ntouros ${ }^{1, *(\mathbb{D})}$, Ioannis Kousis $\left.{ }^{2,3}{ }^{(}\right)$, Anna Laura Pisello ${ }^{2,3}$ and $^{-}$argarita Niki Assimakopoulos ${ }^{1}(\mathbb{C}$ \\ 1 Group Building Environmental Research, Department of Physics, National and Kapodistrian University of \\ Athens, 15784 Athens, Greece; masim@phys.uoa.gr \\ 2 CIRIAF-Interuniversity Research Center, University of Perugia, Via G. Duranti 67, 06125 Perugia, Italy; \\ ioannis.kousis@unipg.it (I.K.); anna.pisello@unipg.it (A.L.P.) \\ 3 Department of Engineering, University of Perugia, Via G. Duranti 97, 06125 Perugia, Italy \\ * Correspondence: vntouros@phys.uoa.gr
}

check for updates

Citation: Ntouros, V.; Kousis, I.; Pisello, A.L.; Assimakopoulos, M.N. Binding Materials for MOF Monolith Shaping Processes: A Review towards Real Life Application. Energies 2022, 15, 1489. https:// doi.org/10.3390/en15041489

Academic Editor: Cai Shen

Received: 25 January 2022

Accepted: 15 February 2022

Published: 17 February 2022

Publisher's Note: MDPI stays neutral with regard to jurisdictional claims in published maps and institutional affiliations.

Copyright: (C) 2022 by the authors. Licensee MDPI, Basel, Switzerland. This article is an open access article distributed under the terms and conditions of the Creative Commons Attribution (CC BY) license (https:// creativecommons.org/licenses/by/ $4.0 /)$.

\begin{abstract}
Metal-organic frameworks (MOFs) could be utilized for a wide range of applications such as sorption, catalysis, chromatography, energy storage, sensors, drug delivery, and nonlinear optics. However, to date, there are very few examples of MOFs exploited on a commercial scale. Nevertheless, progress in MOF-related research is currently paving the way to new industrial opportunities, fostering applications and processes interconnecting fundamental chemistry with engineering and relevant sectors. Yet, the fabrication of porous MOF materials within resistant structures is a key challenge impeding their wide commercial use for processes such as adsorptive separation. In fact, the integration of nano-scale MOF crystallic structures into bulk components that can maintain the desired characteristics, i.e., size, shape, and mechanical stability, is a prerequisite for their wide practical use in many applications. At the same time, it requires sophisticated shaping techniques that can structure nano/micro-crystalline fine powders of MOFs into diverse types of macroscopic bodies such as monoliths. Under this framework, this review aims to bridge the gap between research advances and industrial necessities for fostering MOF applications into real life. Therefore, it critically explores recent advances in the shaping and production of MOF macro structures with regard to the binding materials that have received little attention to date, but have the potential to give new perspectives in the industrial applicability of MOFs. Moreover, it proposes future paths that can be adopted from both academy and industry and can further boost MOF exploitation.
\end{abstract}

Keywords: polymer binders; inorganic binders; metal-organic frameworks; monoliths; shape engineering; applications

\section{Introduction}

Metal-organic frameworks (MOFs) are organic-inorganic hybrid crystalline microporous materials [1]. They consist of positively charged metal ions interconnected with organic ligands [2]. This regular array of metal ions can therefore be formed as a network with up to three dimensions [3]. MOFs are typically characterized by high porosity, low density, and excellent biocompatibility [4]. These properties render them excellent candidates for applications related to sorption, catalysis, chromatography, energy storage, sensors, drug delivery, and nonlinear optics [5-7]. Recently, apart from an in-lab investigation, MOFs have been examined for industrial applications as well. In fact, the large production of a small number of MOFs, such as HKUST-1, ZIF-8, MOF-5, MIL-101, and MOF-177, has been successful and they are currently available on the market [8]. However, in order to develop MOF materials of high efficiency into real life applications, high-tech and sophisticated engineering is necessary for tuning their chemical structure and, hence, their properties at the macroscopic scale [9]. For example, at an industrial scale, properties such as the size and the shape of the corresponding MOF have profound effects on both the 
performance and the processes of the final application, and therefore need to be tailored accordingly [10].

Conventional MOFs are typically synthesized in the form of a crystalline powder with crystallite sizes that range from the nano- to hundreds of micron-scale [11-15]. Nevertheless, MOFs in powder form cannot be easily utilized in industrial applications. In fact, it is reported that a MOF powder may decrease the pressure within a pipeline, reduce, or even completely block the flow [16]. It can also lead to abrasion owing to powder blowing, while the significant reduction of the pure MOF component is also reported due to powder application. Moreover, other reported issues related to MOF powder are dustiness, clogging, and transfer and handling impediment [8,17]. Aiming to overcome these intrinsic issues that MOF powders are prone to, several other synthesis protocols have been tested and evaluated for industrial applications. These synthetic formulation methodologies aim to agglomerate MOF crystallites and shape them into granules, films, foams, gels, monoliths, tablets, or pellets $[18,19]$.

The main criteria for choosing the appropriate synthetic methodology for industrial scale applications of MOFs are their mechanical strength, surface area, chemical stability, and the binder used [20]. Good mechanical strength is necessary for withstanding the pressure exerted by a reactor or column in which the gas flow takes place for gas absorption or separation, catalysis, and similar applications [8,21]. However, MOFs in powder form are not suitable for such applications due to poor mechanical performance, and therefore, they need to be shaped with respect to the desired applications and their process conditions [22,23]. Apart from the mechanical properties, the shaped MOF should have a sufficient size for maintaining the diffusion effect among particles and should maintain as much as possible the porosity and crystallinity of the powder form [5]. Thus, several comparative techniques have been applied for ensuring the good porosity of the developed MOF structures such as those explored by Lorignon et al. in their respective review study [24]. Ensuring the chemical stability of the developed MOF is also crucial. In fact, particularly when the performance of a MOF depends on the $\mathrm{pH}$, chemical stability tests should be carried out for selecting the appropriate binder [25-27]. Choosing the appropriate binder is of high importance, since it ensures the good performance of MOF materials. In fact, MOFs typically lack cohesive force and their crystallinity/porosity can be easily damaged when high pressure is applied. Therefore, in many cases, a binder is applied during their synthesis for reducing the energy and thus improving the efficiency of the process [8].

Several shaping methods are reported within the literature and are typically categorized as (i) non-pressurized processes without binders [28], (ii) pressurized processes without binders [29], (iii) pressurized processes with binders [30], and (iv) non-pressurized processes with binders [31]. The resulting structures of shaped MOFs vary with respect to the application and can be monoliths, pellets, tablets, foams, or granules. For instance, granulation is a conventional non-pressurized technique for agglomeration shaped MOF powders without modifying the chemical characteristics [32]. The addition of binders, such as graphite, silica, and cellulose ester, has been found to enhance the mechanical stability, yet it may decrease the effective surface area of the MOF since the binder may cover the crystals' surface. Pelletization is a pressurized particle agglomeration technique involving applying pressure to powders, either by adding a binder (wet pelletization) or not (dry). Similar to the agglomeration techniques, although the addition of a binder may improve the mechanical stability of the MOF pellet, it could also decrease the surface area of the MOF as it blocks the pores [33].

Since their introduction in the late 1990s [34], MOFs have been utilized in numerous applications [35]. Given the blossoming research around MOFs, today's questions might find their answers sooner than expected, as experiments or real-life applications of MOFs surface rapidly [36]. MOFs' intrinsic features may make them suitable for applications in sectors in which these materials might not have had traditional uses. For example, a sector in which there is much space for improvement with regard to the applications MOFs might 
be suitable for is the building sector (i.e., to improve the indoor air quality, in filters for air purification, in dehumidifiers, integrated into heat transformation cycles for heating and cooling applications, natural gas storage, $\mathrm{CO}_{2}$ capture and storage); however, given the powdery nature of MOFs, as is the case in most industrial sectors, it is still not possible for MOFs to be integrated into the envelopes of buildings or in their systems, and as a result, there are few applications that link MOFs' intrinsic characteristics with the elements of a building (e.g., the walls, systems, and interior decoration objects). Bearing this in mind, the solution to pave the way for MOFs to find their position within the building stock and in other industrial topologies might be hidden due to the lack of information on how to turn powder into a monolith [37], which would make it easier to find an application such as hydrogen or natural gas storage [38-40]. Within this context, we conducted a literature review with regard to the binders used for MOF shape processing into monoliths, granules, or pellets, since their ease of handling and more rigid nature compared to thin films, foams, and gels make them more suitable for in-house applications.

\section{Materials and Methods}

A synthetic approach is followed in the methodology design of this review study (Figure 1). In this review, we aggregated and assessed the outcomes from a set of strategically chosen target publications in order to juxtapose the results of diverse experimental investigations. Evidence-based research methodologies that aim to provide consolidated outcomes, such as identifying scientific gaps/challenges and clearing the path for future breakthroughs in the relevant sector, were included. In this approach, the following four sub-steps were included in order to reduce biases and random errors:

1. Identify a scientific problem that must be solved.

2. Establish precise inclusion/exclusion requirements for studies related to the topic under consideration.

3. Conduct a critical analysis of the studies that have been chosen.

4. Draw a conclusion to the research blank spots and suggest future directions.

Initially, the next research question was outlined as the major impetus of this systematic review study:

(a) What are the most suitable binding materials for MOF monolith shape engineering processes such as granulation and pelletization?

As a result, for a more precise investigation, the sub-questions below were put in place.

i. What are the recent advances in MOFs granulation and pelletization shape engineering processes?

ii. In what kind of applications were the engineered products used?

For the purposes of this study, Web of Science (WoS) and Scopus were considered the principal online search engines. Furthermore, Google Scholar was used to locate (a) grey literature relevant to the research problem, (b) key researchers' work from the author's perspective, and (c) cited articles encountered in previously reviewed studies within the presented review. The web search was conducted between December 2021 and January 2022.

Following this, unique search phrases linked to "binders", "monoliths", and "shape engineering processes" for MOFs were defined and merged for use in academic databases using the logical operators "and" and "or". The results from both online scholarly databases were then combined and repetitions were checked. Inclusion criteria were then applied to the remaining papers to determine whether or not they were eligible for inclusion in the analysis. No time-frame exclusion parameters were used in order to capture the continuity of the advances in the field through time. Despite this, most of the papers analyzed were from 2017 to 2021. 


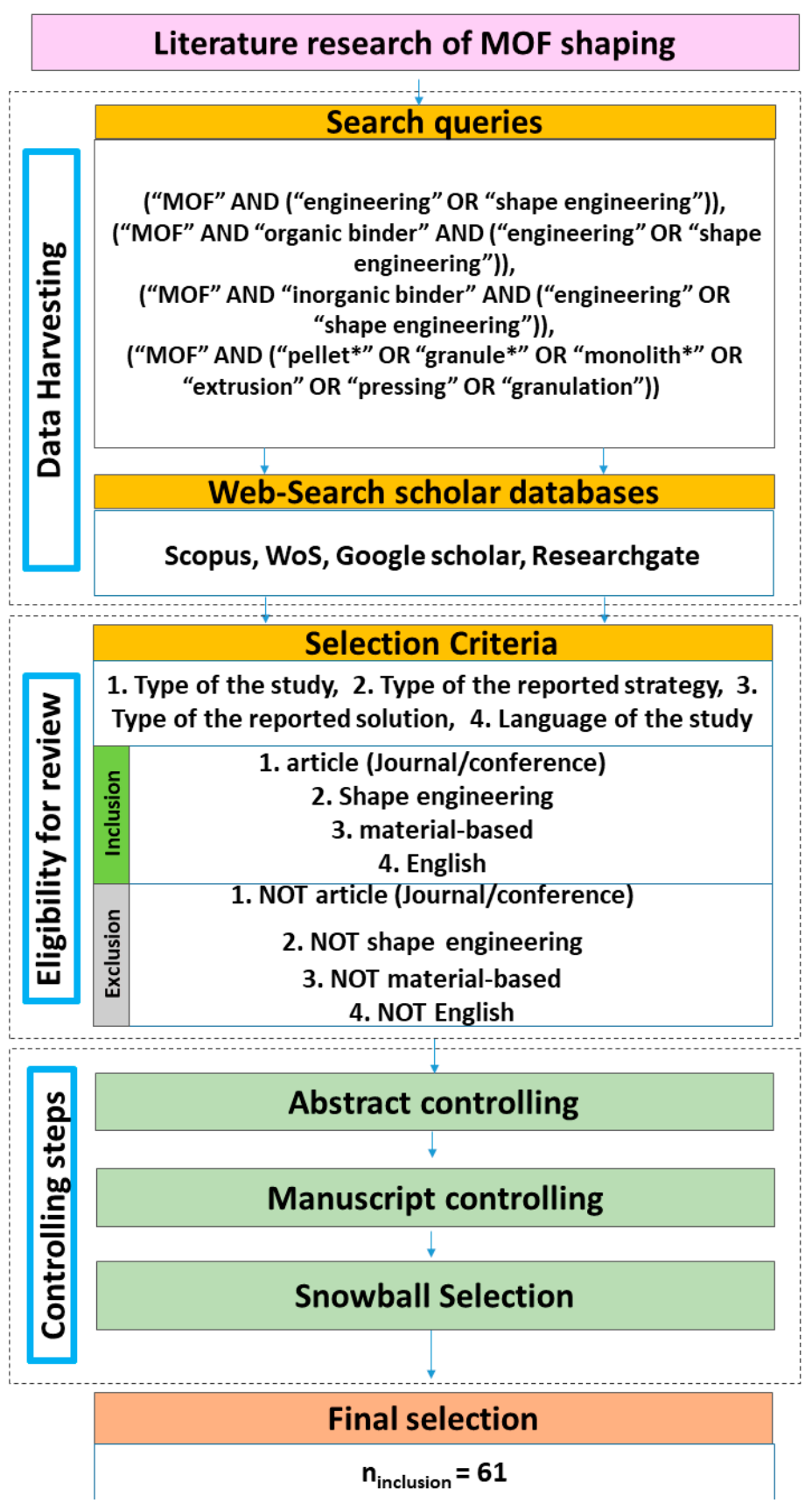

Figure 1. Methodology flowchart.

Eventually, three screening procedures were implemented. Studies both for binders and shaping processes were either included or excluded in the first phase by scanning the respective abstracts, and in the second phase by continuing to read the entire article. The articles were collected using a snowball selection method in the final screening stage [41]. More specifically, several articles were not discovered immediately using the keyword search results, but rather through the reference lists of the publications chosen in the second screening test, and their results were deemed significant. In the end, the total number of articles included in the study was 61.

In addition, the VOS Visualizer tool [42] was used to refine the abovementioned search terms in order to explore the way multi-objective optimization (MOO) models [43] are used throughout the MOF shape engineering processes. The artificial intelligence-based tool puts the keywords provided in order as well as the elements found in the articles' titles and 
abstracts, and then performs a classification to cluster the most frequent words into groups (Figure 2).

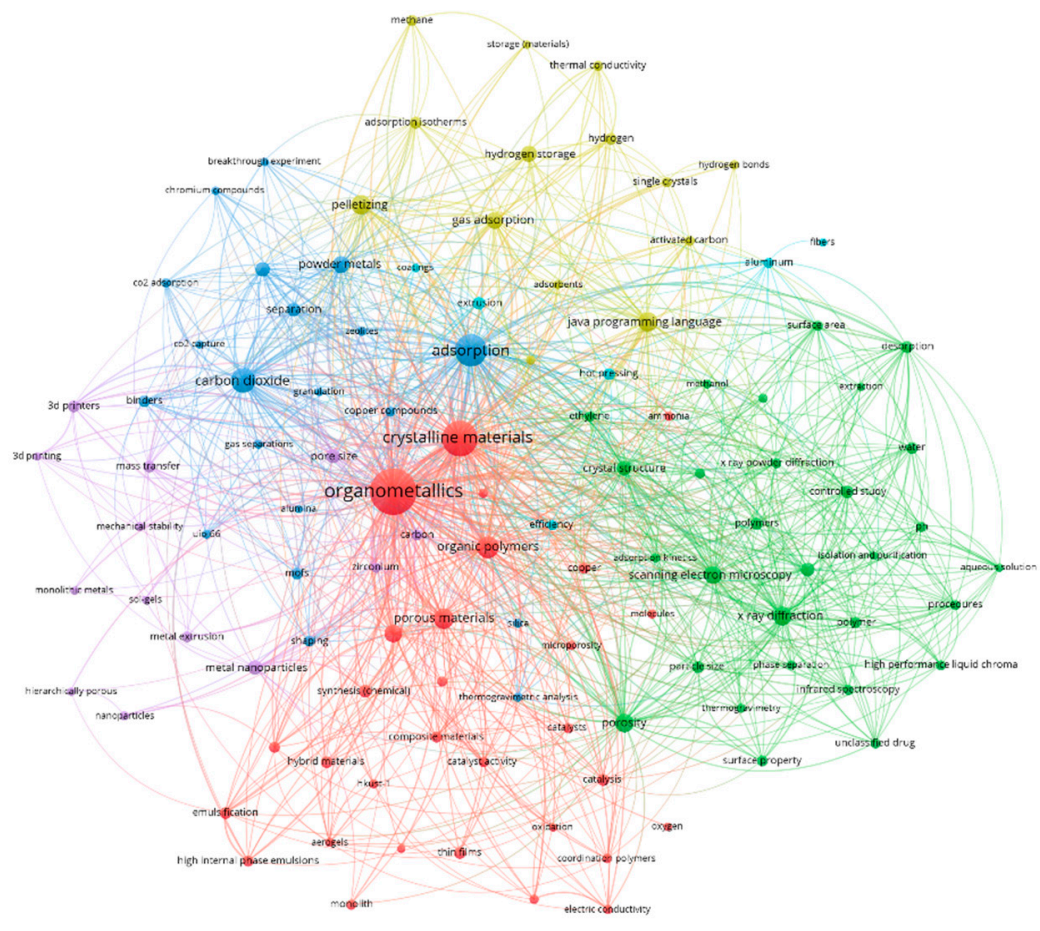

Figure 2. Clustering of keywords set by the authors, and words found in the selected articles' titles and abstracts. (Source: https:/ /www.vosviewer.com/, accessed on 24 January 2022).

\section{Findings from Literature}

MOFs are usually shaped through approaches such as extrusion (Figure 3), granulation (Figure 4) or compression (Figure 5) that have traditionally been utilized to shape other porous materials like zeolites or porous carbons. The main shaping procedure involves (i) mixing the MOFs with adhesive agents; (ii) forming the MOF powder-additives paste into a body; (iii) removal of solvents; and (iv) thermal treatment of the macrostructure, whereas the main criteria for shape engineering the MOFs are mechanical strength, surface area and porosity, and chemical and thermal stability. Extrudates in the form of pellets, thin wafers, tablets, monoliths, beads, spheres, or granules are the most popular forms of MOFs macrostructures. In order to attain a sufficient mechanical strength, most of these structures require an adhesive agent or binder that allows them to behave as a shaped body instead of a powder. Interestingly, there are occasions in which monoliths are produced by applying high pressure to the powder in the absence of any binding agent; however, this applies to MOFs that can withstand high compression forces without losing their porosity and crystal structure. Thus, in most cases, adding an organic and/or an inorganic binder into slurry MOF pastes is necessary for the macrostructure's mechanical strength and chemical and thermal stability in order for a rigid and robust body to be shaped that maintains its porous characteristics. For example, when selecting the proper binder, its chemical and physical characteristics (e.g., solubility, viscosity, chemical bonding groups, temperature of calcination) should be considered in relation to the MOF's characteristics, as the former may influence the latter, and as a result, the shaped body might not be as effective as expected in the application for which it was initially designed. Therefore, a good knowledge of MOFs' characteristics when shaped into monoliths, as well as the requirements of the target application, will further help in the selection of a successful binder among organic (i.e., 
polymers, cellulose, sucrose) and inorganic (i.e., $\rho$ alumina, clays, silica) binders, or may even indicate binderless procedures.

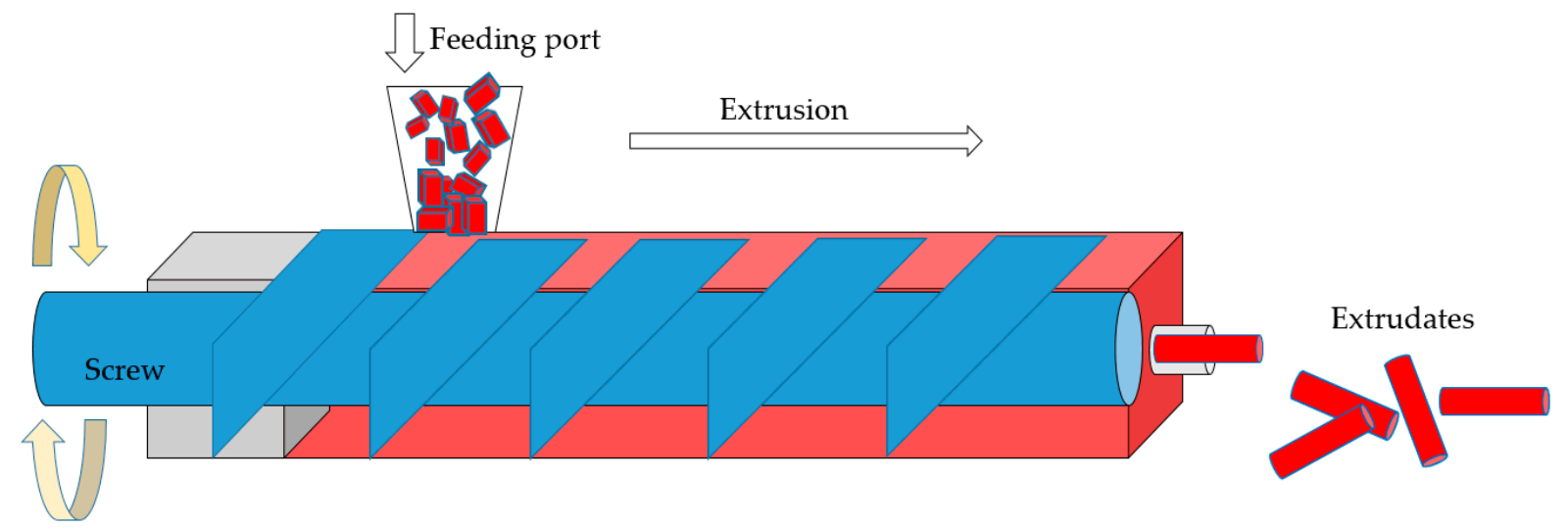

Figure 3. Schematic illustration of a single screw extrusion process and the formed extrudates.

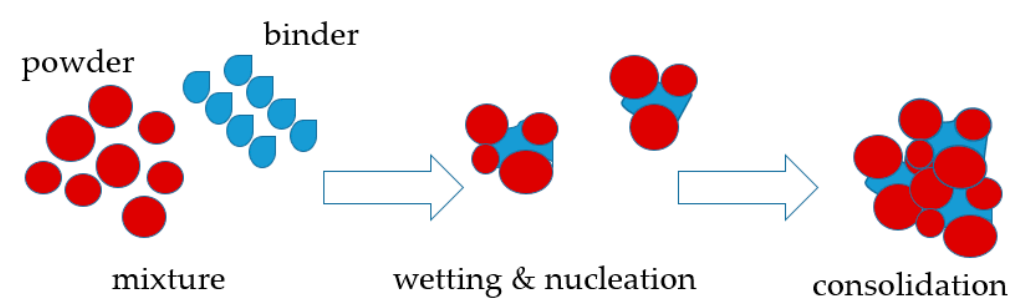

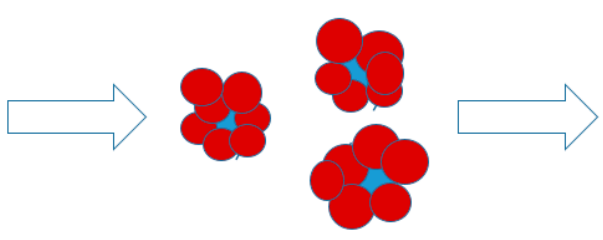

breakage \& attrition

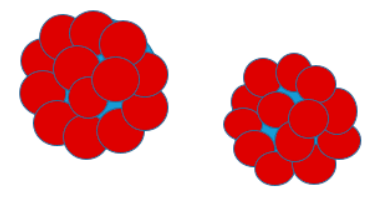

granules

Figure 4. Schematic illustration of a wet granulation process.

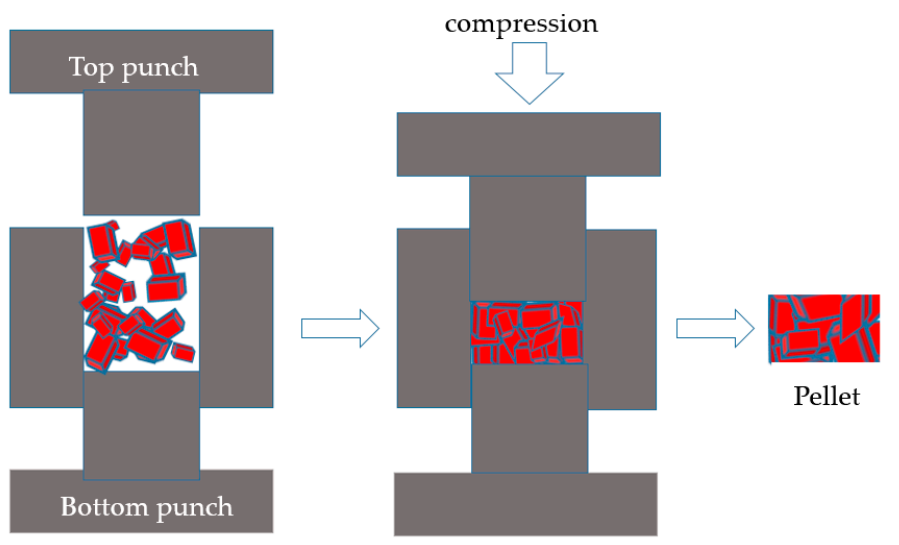

Figure 5. Schematic illustration of a pressing procedure and the formed pellet.

\subsection{Processes with Organic Binders}

The shaping processes of MOFs into monoliths, granules, or pellets usually utilize polymer-type adhesive agents, as this type of binder is easily mixed with MOFs, inducing non-covalent bonding (i.e., hydrogen bonding); in addition, they are soluble to volatile agents [44]. In general, organic binders are synthesized by polymers with a chain-like structure of various lengths, where polar groups exist [45]. The most widely used polymertype binders in MOF shaping processes is polyvinyl alcohol (PVA) and polyvinyl butyral 
(PVB). PVA, with its molecular formula being $\mathrm{C}_{2} \mathrm{H}_{4} \mathrm{O}$, is a white powder that has good solubility in water, is less soluble in ethanol, and is insoluble to most organic solvents. This hydrophilic binder has a melting point between 212 and $267^{\circ} \mathrm{C}$, depending on the degree of hydrolysis of the polyvinyl acetate during its production $[46,47]$. On the other hand, PVB $\left(\mathrm{C}_{16} \mathrm{H}_{28} \mathrm{O}_{5}\right)$, a white powder synthesized from PVA and butyraldehyde with a melting point in the range of $165-185^{\circ} \mathrm{C}$, is insoluble in water, but soluble in solvents frequently used in MOF production, such as ethanol, methanol, and DMF; however, its solubility is strongly dependent on the vinyl alcohol content $[47,48]$.

Less frequent binders used in MOF shaping processes are polyethersulfone (PES), polyvinyl pyrrolidone (PVP), methyl cellulose (MC), and hydroxypropyl cellulose (HPC). PES, $\left(\mathrm{C}_{12} \mathrm{H}_{8} \mathrm{O}_{3} \mathrm{~S}\right)_{\mathrm{n}}$, comes in light amber pellets. It is insoluble in water, but soluble in high polar solvents. It is the most temperature-resistant thermoplastic commercially available; PES absorbs moisture due to its highly hygroscopic sulfone groups [49,50]. PVP, $\left(\mathrm{C}_{6} \mathrm{H}_{9} \mathrm{NO}\right)_{\mathrm{n}}$, also named povidone, is soluble in water as well as in ethanol and methanol. It comes as a white hygroscopic powder and melts at $160^{\circ} \mathrm{C}$ [51]. MC is a hydrophilic white or yellow-white powder, with a melting point in the range of $290-305^{\circ} \mathrm{C}$. Interestingly, $\mathrm{MC}$ is soluble in cold water, but insoluble in hot water or ethanol [52]. Finally, HPC is a white to cream powder that melts at $371{ }^{\circ} \mathrm{C}$ and is soluble in water and organic solvents such as methanol and ethanol [53]. As seen, organic binders' high melting points that allow for MOFs' heat treatment or drying, and their solubility in water and/or in organic solvents frequently used in MOF synthesis, make them promising candidates as adhesive agents that provide the required mechanical stability in MOFs' shaped engineered structures. Zheng et al. used PVB to pelletize TIFSIX-2-Cu-I, SIFSIX-3-Ni, GEFSIX-2-Cu-i, and SIFSIX-2-Cu-I MOFs and the process was deemed to have a great potential for industrial applications [27]. It was found that although PVB reduced MOFs' surface area $(2.9 \%, 17.5 \%$, $12.7 \%$, and $15.2 \%$, respectively), it had negligible influence on the adsorption of $\mathrm{C}_{2} \mathrm{H}_{2}$, whereby it did not severely affect the structure of the MOFs. In the same study, Mg-MOF-74, HKUST-1, and MIL-101-Cr were also pelletized with PVB as the binding material and then tested for their $\mathrm{CO}_{2}$ adsorption performance, showing that they kept the characteristics of $\mathrm{CO}_{2}$ adsorption capacity; for $90 \%$ of the loaded pellets with MOF content, $11.2 \%, 13.6 \%$, and $19.3 \%$ reductions in $\mathrm{CO}_{2}$ adsorption quantity were observed, respectively. Gaikwad et al. also used PVB (4\%) to shape MOF-177 and MOF-177-TEPA-20\% powder samples into pellets, and reported a reduction in $\mathrm{CO}_{2}$ uptake for both samples due to pore blockage and impacts on crystallinity as a result of the process. The MOF-177-TEPA-20\% pellet adsorbed $3.3 \mathrm{mmol} / \mathrm{g}$ of $\mathrm{CO}_{2}(4 \mathrm{mmol} / \mathrm{g}$ in powder form $)$, which was 5.8 times higher than that of the pristine MOF-177 pellet [54]. Taddei et al. used PVB, PVA, and sucrose as binders to form MOF-801 pellets using the single screw extruder method. While the sucrose pellets were brittle, the PVA and PVB pellets had good mechanical stability, with PVB showing the highest durability in drop and shake tests. PVB pellets prepared under lower compression (146 MPa for $15 \mathrm{~s}$ ) were found to have better $\mathrm{CO}_{2}$ working capacity than those prepared under higher compression (438 MPa, $15 \mathrm{~s}$ ) [55]. Sucrose was also used as adhesive agent $(10 \mathrm{wt} \%)$ for pelletizing active Zr-MOF crystals for hydrogen storage applications [56]. The shaped Zr-MOF with the use of a centrifugal granulator had good mechanical strength, but lost almost half of the $\mathrm{H}_{2}$ uptake and surface area compared to the pristine powder. In Chanut et al., a polymer-binder mixture containing PVA and PVB was used to shape $\mathrm{UiO}-66(\mathrm{Zr}), \mathrm{UiO}-66(\mathrm{Zr})-\mathrm{NH}_{2}, \mathrm{MIL}-100(\mathrm{Fe})$, and MIL-127(Fe) MOF granules and test them on their adsorption of various gases such as methane, carbon dioxide, carbon monoxide, and others. The granules showed decreased BET areas in the order of $10 \%$ or higher for MIL-100(Fe) and UiO-66(Zr), whereas this reduction for the other two granules was in the order of $4-5 \%$. Interestingly, when activating MIL-127(Fe) powder and granules, higher enthalpies were observed for the powder, and this might be an indication that the binding material may act as a "stabilizer" in a greater oxidized state [57]. Hindocha and Poulston utilized PVA (2 wt \%) to form CPO-27(Ni), MIL-100(Fe), and Cu-BTC granules through wet granulation and tested their ammonia adsorption performance for applications in 
respiratory protection filters [58]. CPO-27(Ni) and MIL-100(Fe) displayed similar uptake capacities for ammonia (51 and $50 \mathrm{mg} / \mathrm{g}$, respectively), whereas for Cu-BTC, this was equal to $19 \mathrm{mg} / \mathrm{g}$.

In a notable study [29], ZIF-8 crystals were shaped into resistant pellets by employing 55 different binder recipes, i.e., cellulose-acetate (CA), polyvinylchloride (PVC), polyvinylformal (PVF), polyetherimide (PEI), and polystyrene (PS). For the formulation of the structures, the researchers followed an extrusion-crushing-sieving (ECS) method. The binder recipes were evaluated with respect to their stability in terms of mechanical, acid/base, hydrothermal, and life span. The results of the chemical stability and mechanical strength tests showed that the PVF binder outperformed the others. In another study, also conducted by Cousin-Saint Remi et al., a composite ZIF-8/PVF material with an $85 \%$ MOF content in the form of beads was developed that demonstrated high crushing strength $(3.09 \mathrm{~N} / \mathrm{Pc})$ and thermal stability up to $200^{\circ} \mathrm{C}$. Again, the amount of binder in the material proportionally reduced its adsorption capacity [59]. Similarly, Abbasi et al. utilized a phase inversion method and polyethersulfone as a binder to develop rigid, easy to handle, and recyclable ZIF-8/PES composite beads for oil sorption applications, which was able to retain up to $88 \%$ of its sorption capacity after five regeneration cycles [60]. Hastürk et al., through freeze-casting, successfully developed hydrothermal stable Alfum, MIL-160(Al), and MIL-101(Cr) monoliths using various polymer binders. From those, the monoliths with the PVA binder showed the highest mechanical stability; PEI exhibited the least, given that it is a liquid at room temperature, whereas sodium polyacrylate (PAANa) was the most hydrophilic, according to its water vapor uptake in contrast to polyethylene glycol (PEG) [61].

In [62], $\mathrm{Cu}_{3}(\mathrm{BTC})_{2}$ was combined with PVA to form pellets. After pelletizing, the structural integrity was preserved, but the textural qualities decreased to some extent. The $\mathrm{Cu}_{3}(\mathrm{BTC})_{2}$ powder was very hydrophilic, and following pelletization, its water-sorption capacity decreased. Despite a minor decrease in saturation capacity compared to the powders, $\mathrm{CO}_{2}$ adsorption employing ground/sieved $\mathrm{Cu}_{3}(\mathrm{BTC})_{2}$ pellets provided a better breakthrough pattern. Finsy et al. investigated the adsorption of $\mathrm{CH}_{4} / \mathrm{CO}_{2}$ mixtures from MIL-53(Al) pellets produced with a PVA binder. As shown, the use of polyvinyl alcohol as a binder leads to a $32 \%$ reduction in total capacity, as demonstrated by $\mathrm{N}_{2}$ adsorption isotherms [63]. In another study, a novel approach employed a Pickering High Internal Phase Emulsion (HIPE) template to prepare UiO-66/PVA monoliths with PVA playing a key role, not only as an adhesive, but also as a stabilizer to Pickering HIPEs [64]. According to Grande et al., when UTSA-16 was combined with PVA as binder and a mixture of water and propanol as a plasticizer and then extruded, it was revealed that if more PVA is used, the crushing strength increases significantly at the expense of a reduction of the surface area; a content of $3 \%$ of PVA results in a surface area reduction of $5 \%$, given that the sample is activated at $393 \mathrm{~K}$ [65]. Based on the same shaping technique, Águeda et al. prepared UTSA-16 extrudates with PVA and measured the adsorption equilibrium and kinetic data of hydrogen, methane, and other important gases, and then simulated a pressure swing adsorption process for hydrogen purification from the steam methane reforming off-gases [66]. According to the study, a higher than $93 \%$ recovery of hydrogen can be achieved with $99.9 \%$ purity.

In another study, Alfum and MIL-101(Cr) were formatted into monoliths with PVA as an adhesive material using a phase separation approach, whereby in order to maintain the monolith shape and avoid shrinkage, vacuum drying is preferred over supercritical and freeze-drying [67]. Edubilli and Gumma [68] pelletized UiO-66 powder with PVA as a binding agent (15 wt\% PVA in water) and it was observed that about $9.3 \mathrm{wt} \%$ of PVA was required to make mechanical stable pellets against the drop test. As noted, the formation into pellets decreased the $\mathrm{CO}_{2}$ gravimetric adsorption capacity by about $14 \%$. PVA was also used as an adhesive agent to form MIL-101(Cr) tablets in a study [69] that addressed the characteristics of MIL-101(Cr) as a methanol adsorbent for adsorptive heat transformation (AHT) cycles, a technology for heating and cooling. As revealed, 
adding PVA to MIL-101(Cr) did not impact its adsorption equilibrium with methanol vapor. Delgado et al. reported a smaller than $3 \%$ decrease in surface area for a PVA loading of $2.9 \%$ in ZIF-8 and HKUST-1 extrudates [70]. The findings showed that the nitrogen adsorption capacity of the extrudates drops as the PVA concentration increases, but the curve of the adsorption isotherms is not altered, showing that the PVA molecule does not reduce the sample's micropore volume and, hence, is not maintained in the MOF's pores. Pellets with $80 \%$ MOF content, in the order of millimeters, were produced through the freeze granulation approach in [71] for sorption-driven chiller systems with PVA as an adhesive. The four different MOF pellets (MOF-801, UiO-66, Alfum, and MIL-160(Al)) were highly resistant to mechanical stress exerted from $14 \mathrm{~N}$ up to $79 \mathrm{~N}$, while the MOFs maintained their uptake capacity and porosity. Lorignon et al. obtained MIL-96(Al) from Li-Ion battery waste through a Pickering emulsion template, added PVA, and produced oval, rice-like monoliths. The PVA stabilized the emulsion and increased the creation of pore throats, which enhanced the porous network's interconnections [72]. Khabzina et al. [31] reported on an upscaled fabrication and shaping of a zirconium-based $\mathrm{MOF}$, i.e., $\mathrm{UiO} 66-\mathrm{COOH}$, for $\mathrm{NH}_{3}$ air purification. Freeze granulation and extrusion techniques were chosen for the shaping. Through freeze granulation, they developed MOF beads, while with extrusion they developed MOF extrudates, both of a particle size ranging between 425 and $600 \mu \mathrm{m}$. For the shaping, they used either PVA or polysiloxane (silicon resin) as the binder.

Kreider et al. reported on the developments of a prototypical MOF, made with MOF-5 and acrylonitrile butadiene styrene (ABS), aiming to address one of the main drawbacks of MOFs, i.e, processibility [73]. The shaping into a filament was done with extrusion at $195^{\circ} \mathrm{C}$ and the composite was fabricated with a commercially available thermoplastic $3 \mathrm{D}$ printer. The results showed that the incorporation of MOFs into polymers made with conventional 3D printers can maintain their intrinsic properties. Recently, polyvinylpyrrolidone (PVP) was used as the binding agent to form ELM-11 pellets [74]. As shown, the characteristic stepwise $\mathrm{CO}_{2}$ uptake of the pristine powder was lost after the formation into pellets and a slacking of the gate adsorption was observed, which is considered to take place due to the weight of the polymer binder. In other work [75], PVP ( $2 \%)$ was utilized as a binding agent in a MIL-100(Fe)/RD silica gel composite monolith produced under compression with regard to an ultra-low heat-driven atmospheric water harvesting $(\mathrm{AWH})$ system; the performance of the system was significantly increased compared to the silica gel-based AWH system-up to $187 \%$.

Park et al., in a notable study, shaped MOF/polyvinylidene fluoride (PVDF) beads via a phase inversion approach and observed that the uptake $\mathrm{CO}_{2}$ capacity of the beads with $40 \%$ PVDF content was maintained after exposure to $60 \%$ humidity at room temperature for up to 30 days, which is a promising result for $\mathrm{CO}_{2}$ capture applications in indoor environments [76]. Munusamy et al. prepared granules of MIL-101(Cr) with sodium salt of carboxyl methyl cellulose (CMC) and starch as a binder and conducted volumetric sorption measurements of $\mathrm{CO}_{2}, \mathrm{CH}_{4}, \mathrm{~N}_{2}$, and $\mathrm{CO}$ [77]. It was observed that the selectivity of gases for granules and powder did not change, although the uptake capacity of the granules reduced by $50 \%$ compared to the powder. Kriesten et al. reported the extruded pellets of MIL-53 and MIL-53- $\mathrm{NH}_{2}$ employing methyl cellulose (MC) as an adhesive [78]. As revealed, the maximum mechanical stability was reached at $5 \%$ binder content, whereas the addition of $\mathrm{MC}$ did not change the pore breathing behavior during $\mathrm{CO}_{2}$ uptake, showcasing the potential that shaped MOFs have for use in technical applications. Regufe et al. [79] reported on the fabrication and carbon dioxide $\left(\mathrm{CO}_{2}\right)$, carbon monoxide $(\mathrm{CO})$, nitrogen $\left(\mathrm{N}_{2}\right)$, methane $\left(\mathrm{CH}_{4}\right)$, and hydrogen $\left(\mathrm{H}_{2}\right)$ adsorption properties of MOF granulates, made with amino-functionalized titanium terephthalate MIL-125(Ti)_NH $\mathrm{NH}_{2}$ for syngas treatment applications aiming for hydrogen production. The powder was firstly finely ground, then mixed with a polyvinyl group binder $(3 \mathrm{wt} \%)$ and finally shaped with a homemade fan-type granulator through a wet granulation process.

In [80], three M-gallate $(\mathrm{M}=\mathrm{Mg}, \mathrm{Co}, \mathrm{Ni})$ materials were pelletized $(95.2 \%$ content of MOF) employing hydroxypropyl cellulose (HPC) as a binding agent. The HPC enhanced 
the mechanical stability of the shaped pellets, which displayed a high regenerative ability. Experiments on adsorption showed a good separation performance for both $\mathrm{C}_{2} \mathrm{H}_{4} / \mathrm{C}_{2} \mathrm{H}_{6}$ and $\mathrm{C}_{2} \mathrm{H}_{2} / \mathrm{C}_{2} \mathrm{H}_{4}$ mixtures, whereby the $\mathrm{C}_{2}$ hydrocarbon uptake capacity of the pellets is not easily influenced after molding. HPC was also used as adhesive in the wet granulation of ZIF-8 with a compact high-shear mixer in [81]; when the binder content was increased, the adsorption capacity of the ZIF-8 granules fell marginally. The gate adsorption behavior of ZIF-8, on the other hand, remained nearly constant following the granulation procedure. In [82], MIP-202 was mixed with HPC and water and then the viscous substance was packed into a $2.5 \mathrm{~mL}$ syringe without a needle and squeezed into strips, which were then dried and cut into pellets. The shaped pellets presented great cyclic stability, easy regeneration, moderate water and moisture stability, and high $\mathrm{CO}_{2} / \mathrm{N}_{2}$ and $\mathrm{CO}_{2} / \mathrm{CH}_{4}$ selectivity. As a result, MIP-202 pellets are regarded as a promising porous material for real-life applications of $\mathrm{CO}_{2}$ capture. Wickenheisser et al. [83], studying MIL-100(Fe,Cr) and MIL-101(Cr) for water adsorption applications, produced MIL/xerogel composite monoliths by employing a polymerized resorcinol-formaldehyde xerogel as the binder and demonstrated the water uptake these monoliths can achieve. The results showed that the monoliths have good stability and adsorption, which make them good candidates for heat transformation applications. As indicated, the blocking of pores from the binder could largely be avoided by the pre-polymerization of the native xerogel solution before mixing it with the powder. Bazer-Bachi et al. [84] investigated the effect of the fabrication process on the characteristics and stability of the catalytic activity of three types of MOF, i.e., ZIF-8, HKUST-1, and SIM-1, shaped by compression values from 0.3 to $5 \mathrm{kN}$. The outcomes showed that the higher the pressurization, the higher the mechanical strength, but the lower the porosity of the developed pellet. In Table 1, MOF macrostructures that utilize organic binders are summarized.

Table 1. Summary of shaped MOFs with organic binders.

\begin{tabular}{|c|c|c|c|c|c|c|}
\hline MOF & Binder $(w t \%)$ & Shape & $\begin{array}{l}\text { S } \\
\quad\left(\mathrm{m}^{2} \mathrm{~g}^{-1}\right)\end{array}$ & $\begin{array}{l}\text { SBET }_{\text {BEdy }} \text { Body } \\
\left(\mathrm{m}^{2} \mathrm{~g}^{-1}\right)\end{array}$ & Application & Reference \\
\hline TIFSIX-2-Cu-i & PVB (10\%) & Pellet & 740 & 719 & Gas separation and storage & [27] \\
\hline SIFSIX-3-Ni & PVB $(10 \%)$ & Pellet & 360 & 297 & Gas separation and storage & [27] \\
\hline GEFSIX-2-Cu-i & PVB $(10 \%)$ & Pellet & 755 & 659 & Gas separation and storage & [27] \\
\hline SIFSIX-2-Cu-i & PVB (9\%) & Pellet & 808 & 685 & Gas separation and storage & [27] \\
\hline ZIF-8 & PEI $(14 \%)$ & Pellet & - & - & Gas adsorption and separation & [29] \\
\hline ZIF-8 & PVC $(23 \%)$ & Pellet & - & - & Gas adsorption and separation & [29] \\
\hline ZIF-8 & PVF $(20 \%)$ & Pellet & - & - & Gas adsorption and separation & [29] \\
\hline UiO66-COOH & PVA $(4 \%)$ & Bead & 710 & 359 & $\mathrm{NH}_{3}$ air purification & [31] \\
\hline $\mathrm{UiO} 66-\mathrm{COOH}$ & $\begin{array}{l}\text { Polysiloxane } \\
\qquad(5.5 \%)\end{array}$ & Extrudate & 710 & 418 & $\mathrm{NH}_{3}$ air purification & [31] \\
\hline MOF-177 & PVB (4\%) & Pellet & 2784 & - & $\mathrm{CO}_{2}$ adsorption & [54] \\
\hline MOF-177-TEPA-20\% & PVB (4\%) & Pellet & 585 & - & $\mathrm{CO}_{2}$ adsorption & [54] \\
\hline MOF-801 & PVB (5\%) & Pellet & 899 & 569 & $\mathrm{CO}_{2}$ and $\mathrm{H}_{2} \mathrm{O}$ adsorption & [55] \\
\hline $\mathrm{Zr}-\mathrm{MOF}$ & Sucrose $(10 \%)$ & Pellet & 1367 & 674 & $\mathrm{H}_{2}$ storage & [56] \\
\hline $\mathrm{UiO}-66(\mathrm{Zr})$ & PVA/PVB (3\%) & Granule & 1065 & 1017 & Gas adsorption & [57] \\
\hline $\mathrm{UiO}-66(\mathrm{Zr}) \_\mathrm{NH} 2$ & PVA/PVB (3\%) & Granule & 958 & 795 & Gas adsorption & [57] \\
\hline MIL-100(Fe) & PVA/PVB (3\%) & Granule & 2261 & 2043 & Gas adsorption & [57] \\
\hline MIL-127(Fe) & PVA/PVB (3\%) & Granule & 1181 & 1117 & Gas adsorption & [57] \\
\hline CPO-27(Ni) & PVA $(2 \%)$ & Granule & 937 & 1319 & $\begin{array}{l}\mathrm{NH}_{3} \text { adsorption for Respiratory } \\
\text { protection filters }\end{array}$ & [58] \\
\hline MIL-100(Fe) & PVA $(2 \%)$ & Granule & 1212 & 1172 & $\begin{array}{l}\mathrm{NH}_{3} \text { adsorption for Respiratory } \\
\text { protection filters }\end{array}$ & [58] \\
\hline Cu-BTC & PVA $(2 \%)$ & Granule & 1605 & 147 & $\begin{array}{l}\mathrm{NH}_{3} \text { adsorption for Respiratory } \\
\text { protection filters }\end{array}$ & [58] \\
\hline ZIF-8 & PVF $(15 \%)$ & Bead & - & - & Gas adsorption and separation & [59] \\
\hline ZIF-8 & PES (25\%) & Bead & 1384.4 & 1030.6 & Oil sorption & [60] \\
\hline Alfum & PVA $(20 \%)$ & Monolith & 946 & 612 & Water vapor sorption & [61] \\
\hline MIL-160(Al) & PVA $(20 \%)$ & Monolith & 1134 & 800 & Water vapor sorption & [61] \\
\hline MIL-101(Cr) & PVA $(20 \%)$ & Monolith & 3171 & 2225 & Water vapor sorption & [61] \\
\hline MIL-53(Al) & PVA $(13 \%)$ & Pellet & - & - & $\begin{array}{l}\text { Separation of } \mathrm{CO}_{2} / \mathrm{CH}_{4} \\
\text { mixtures }\end{array}$ & [63] \\
\hline $\mathrm{UiO}-66$ & PVA (1\%) & Monolith & - & - & MOF shape engineering & [64] \\
\hline
\end{tabular}


Table 1. Cont.

\begin{tabular}{|c|c|c|c|c|c|c|}
\hline MOF & Binder (wt $\%)$ & Shape & $\begin{array}{l}\text { S } \\
\quad\left(\mathrm{m}^{2} \mathrm{~g}^{-1}\right)\end{array}$ & $\begin{array}{l}\text { SBET Body } \\
\left(\mathrm{m}^{2} \mathrm{~g}^{-1}\right)\end{array}$ & Application & Reference \\
\hline $\mathrm{Cu}_{3}(\mathrm{BTC})_{2}$ & PVA (-) & Pellet & 1737 & 963 & $\begin{array}{l}\mathrm{H}_{2} \mathrm{O} \text { vapor and } \mathrm{CO}_{2} \\
\text { adsorption/catalysis }\end{array}$ & [62] \\
\hline UTSA-16 & PVA $(0-6.7 \%)$ & Pellet & - & - & $\mathrm{CO}_{2}$ adsorption & [65] \\
\hline UTSA-16 & PVA (-) & $\begin{array}{l}\text { Cylindrical } \\
\text { extrudate }\end{array}$ & - & 805 & $\begin{array}{c}\text { Gas adsorption (high } \\
\text { pressure) } / \mathrm{H}_{2} \text { purification from } \\
\text { SMR off-gases }\end{array}$ & [66] \\
\hline Alfum & PVA $(20 \%)$ & Monolith & 1038 & 786 & Water vapor sorption & [67] \\
\hline MIL-101(Cr) & PVA $(20 \%)$ & Monolith & 2731 & 1820 & Water vapor sorption & [67] \\
\hline $\mathrm{UiO}-66$ & PVA (-) & Pellet & 1378 & 1274 & $\mathrm{CO}_{2} / \mathrm{N}_{2}$ separation & {$[68]$} \\
\hline MIL-101(Cr) & PVA $(10 \%)$ & Grain & 2970 & 2610 & $\begin{array}{c}\text { adsorption heat transformation } \\
\text { cycles }\end{array}$ & [69] \\
\hline ZIF-8 & PVA $(2.9 \%)$ & $\begin{array}{l}\text { Cylindrical } \\
\text { extrudate }\end{array}$ & - & - & $\begin{array}{c}\mathrm{CO}_{2} / \mathrm{H}_{2} \\
\begin{array}{c}\text { Separation } / \text { biohydrogen } \\
\text { purification }\end{array}\end{array}$ & [70] \\
\hline HKUST-1 & PVA $(2.9 \%)$ & $\begin{array}{l}\text { Cylindrical } \\
\text { extrudate }\end{array}$ & - & - & $\begin{array}{c}\mathrm{CO}_{2} / \mathrm{H}_{2} \\
\begin{array}{c}\text { Separation/biohydrogen } \\
\text { purification }\end{array}\end{array}$ & [70] \\
\hline UTSA-16 & PVA $(2.9 \%)$ & $\begin{array}{l}\text { Cylindrical } \\
\text { extrudate }\end{array}$ & - & - & $\begin{array}{c}\mathrm{CO}_{2} / \mathrm{H}_{2} \\
\begin{array}{c}\text { Separation/biohydrogen } \\
\text { purification }\end{array}\end{array}$ & [70] \\
\hline $\mathrm{UiO}-66$ & PVA $(25 \%)$ & Pellet & 1295 & 1031 & $\begin{array}{l}\text { Water adsorption heat } \\
\text { transformation systems }\end{array}$ & [71] \\
\hline Zr-fum & PVA $(25 \%)$ & Pellet & 643 & 479 & $\begin{array}{l}\text { Water adsorption heat } \\
\text { transformation systems }\end{array}$ & [71] \\
\hline Al-fum & PVA $(25 \%)$ & Pellet & 988 & 595 & $\begin{array}{l}\text { Water adsorption heat } \\
\text { transformation systems }\end{array}$ & [71] \\
\hline MIL-160 & PVA $(25 \%)$ & Pellet & 1122 & 866 & $\begin{array}{l}\text { Water adsorption heat } \\
\text { transformation systems }\end{array}$ & [71] \\
\hline MIL-96(Al) & PVA $(0.5 \%)$ & Monolith & 655 & 91 & $\begin{array}{l}\text { Upcycling of Li-ion } \\
\text { batteries/MOF shape } \\
\text { engineering }\end{array}$ & [72] \\
\hline MOF-5 & ABS (1/5/10\%) & $\begin{array}{l}\text { 3D-printed } \\
\text { various } \\
\text { geometries }\end{array}$ & - & - & $\begin{array}{c}\mathrm{H}_{2} \text { adsorption/3D-printed } \mathrm{H}_{2} \\
\text { storage devices }\end{array}$ & [73] \\
\hline ELM-11 & PVP (10/20/31\%) & Pellet & - & - & $\begin{array}{l}\text { Gas storage and separation } \\
\text { Ultra-low heat-driven }\end{array}$ & [74] \\
\hline MIL-100(Fe) & PVP (2\%) & Monolith & 1917 & 1673.7 & $\begin{array}{c}\text { atmospheric water harvesting } \\
(\mathrm{AWH}) \text { system }\end{array}$ & {$[75]$} \\
\hline epn-MOF & $\begin{array}{c}\text { PVDF } \\
(30 / 40 / 50 \%)\end{array}$ & Bead & - & - & $\begin{array}{c}\mathrm{CO}_{2} \text { capture in indoor } \\
\text { environments }\end{array}$ & [76] \\
\hline MIL-101(Cr) & $\begin{array}{l}\text { CMC sodium salt } \\
(5.5 \%) \text { and starch } \\
(5.5 \%)\end{array}$ & Granule & 2471 & 1642 & $\begin{array}{l}\text { Gas }\left(\mathrm{CO}_{2}, \mathrm{CH}_{4}, \mathrm{~N}_{2}, \mathrm{CO}\right) \\
\text { sorption }\end{array}$ & [77] \\
\hline MIL-53(Al) & MC $400(10 \%)$ & $\begin{array}{l}\text { Cylindrical } \\
\text { extrudate }\end{array}$ & 1525 & 1158 & $\mathrm{CO}_{2}$ and $\mathrm{CH}_{4}$ adsorption & [78] \\
\hline MIL-53(Al) & MC $4000(10 \%)$ & $\begin{array}{l}\text { Cylindrical } \\
\text { extrudate }\end{array}$ & 1525 & 1200 & $\mathrm{CO}_{2}$ and $\mathrm{CH}_{4}$ adsorption & {$[78]$} \\
\hline MIL-125(Ti)_NH ${ }_{2}$ & $\begin{array}{l}\text { Polyvinyl group } \\
\qquad(3 \%)\end{array}$ & Granule & - & - & $\begin{array}{c}\text { Syngas treatment aiming for } \mathrm{H}_{2} \\
\text { production }\end{array}$ & [79] \\
\hline Mg-gallate & $\mathrm{HPC}(4.8 \%)$ & Pellet & 638 & 557 & Hydrocarbon separations & [80] \\
\hline Co-gallate & $\mathrm{HPC}(4.8 \%)$ & Pellet & 494 & 480 & Hydrocarbon separations & [80] \\
\hline Ni-gallate & $\mathrm{HPC}(4.8 \%)$ & Pellet & 455 & 425 & Hydrocarbon separations & [80] \\
\hline ZIF-8 & HPC $(0-40 \%)$ & Granule & - & - & MOF shape engineering & [81] \\
\hline MIP-202 & HPC (5\%) & Pellet & 278.6 & - & $\begin{array}{l}\mathrm{CO}_{2} / \mathrm{CH}_{4} \text { and } \mathrm{CO}_{2} / \mathrm{N}_{2} \\
\text { separation } / \mathrm{CO}_{2} \text { capture }\end{array}$ & [82] \\
\hline MIL-101(Cr). & R,F-xerogel (50\%) & Monolith & 3060 & 1350 & Water adsorption & [83] \\
\hline MIL-100(Fe) & R,F-xerogel (42\%) & Monolith & 2200 & 770 & Water adsorption & [83] \\
\hline MIL-100(Cr) & R,F-xerogel (44\%) & Monolith & 1560 & 570 & Water adsorption & [83] \\
\hline ZIF-8 & Cellulose ester (-) & Tablet & 1433 & 1420 & $\begin{array}{c}\text { Catalysis/MOF shape } \\
\text { engineering }\end{array}$ & {$[84]$} \\
\hline HKUST-1 & Cellulose ester (-) & Tablet & 1897 & 453 & $\begin{array}{l}\text { Catalysis/MOF shape } \\
\text { engineering }\end{array}$ & [84] \\
\hline SIM-1 & Cellulose ester (-) & Tablet & 516 & 370 & $\begin{array}{l}\text { Catalysis/MOF shape } \\
\text { engineering }\end{array}$ & [84] \\
\hline
\end{tabular}




\subsection{Processes with Inorganic Binders}

Inorganic binders are less common than the polymer binders; however, they demonstrate high mechanical stability, which provides rigid forms to the shaped structures. Clays, alumina, and silica are widely used inorganic binders in MOF shaping processes. Clays, such as bentonite clays, come in various colored powder forms, are insoluble in water, and when mixed with water, form a colloidal solution and have high melting points; e.g., for bentonite, it is higher than $1200{ }^{\circ} \mathrm{C}$ [85]. Silica $\left(\mathrm{SiO}_{2}\right)$, a white powder also known as silicon dioxide, melts in temperatures higher than $1700{ }^{\circ} \mathrm{C}$, is rather insoluble in water, and is insoluble in ethanol [86]. Alumina $\left(\mathrm{Al}_{2} \mathrm{O}_{3}\right)$ is a popular inorganic binder, with various crystal forms such as $\alpha-, \beta-, \gamma_{-}, \delta$ - and $\rho$ - alumina, which also has the properties of a porous material, with mesoporous alumina exhibiting pores of between 2 and $50 \mathrm{~nm}$ [87]. Alumina, also called aluminum oxide, is a white crystalline powder, insoluble in water, with a melting point higher than $2000{ }^{\circ} \mathrm{C}$ [88]. Inorganic binders can operate in higher temperatures than their polymer counterparts and this is suitable for those materials that require heat treatments at relatively high temperatures.

Zhu et al. examined gas adsorption in shaped ZIF-8 tablets produced from a single push tablet pressing machine utilizing alumina, bentonite, silica, talc powder, SB powder (high-quality pseudo-boehmite), sesbania powder, and MC as binders [89]. The most suitable adhesive agents were found to be SB powder and talc powder, for which a $10-20 \%$ reduction in the uptake capacities $\left(\mathrm{CO}_{2}, \mathrm{CH}_{4}\right.$, and other hydrocarbons) was observed on the shaped ZIF-8, and it is deemed that the shaped forms are able to satisfy the industrial demand. Moreira et al. synthesized UiO-66 tablets and consequently evaluated them in terms of selective adsorption and separation of xylene isomers [90]. The shaping of the tablets was carried out with the use of a rotary press tabletizer with graphite as the binder. Lefevere et al. 3D printed a ZIF-8 monolith with bentonite (16.7 $\mathrm{wt} \%$ ) as an adhesive agent in order to ensure the mechanical and thermal stability of the monolith and MC (16.7 wt\%) to improve the rheology of the extruded paste [91]. As noted, adding bentonite shifts the hysteresis loop of the Ar isotherm on ZIF- 8 . Activating the monoliths at $450{ }^{\circ} \mathrm{C}$ removed $\mathrm{MC}$ and allowed for a high adsorption capacity in a reproducible manner with regard to n-butanol. In a study conducted by Tsalaporta and MacElroy [92], MC and bentonite were used as binders diluted in water to form pelletized UiO-66, ZIF-67, ZIF-8, and HKUST-1. ZIF-8 maintained its crystal structure in the presence of binders and water while ZIF 67 irreversibly lost it; for UiO-66 and HKUST-1, ethanol was used to reconstruct their crystallinity. Hong et al. formed MIL-101(Cr) monoliths with bentonite clay as the binding agent via paste extrusion with a powder-to-binder ratio of 75:25 [93]. To further improve the porosity of the monolith, Licowax $\mathrm{C}$ was added into the paste. Subsequently, the monolith was tested for its $\mathrm{CO}_{2}$ adsorption performance and compared with a 13X Zeolite monolith; the findings revealed that the MIL-101(Cr) monolith capacity outperformed that of $13 \mathrm{X}$ Zeolite by $37 \%$, whereas its $\mathrm{CO}_{2}$ uptake capacity was enhanced as the temperature to regenerate the monolith was increased. In [94], bentonite clay (40 $\mathrm{wt} \%)$ was also used in the single screw extrusion of MIL-101(Cr) paste. The prepared monoliths were mechanically stable, exhibited high $\mathrm{CO}_{2}$ uptake capacity compared to pristine MIL-101(Cr), and they could be regenerated at $150^{\circ} \mathrm{C}$ for repeated adsorption circles, thus making them a good candidate for industrial applications.

Valekar et al. reported on the fabrication of MOF millimeter-scale spheres made with MIL-100(Fe), MIL-101(Cr), UiO-66(Zr), and UiO-66(Zr)_NH ${ }_{2}$ through the wet granulation method [30]. The millimeter-scale pellets were shaped with the use of a hand-made pan-type granulator, by mixing the MOF-powder with mesoporous $\rho$-alumina (MRA) as a binder and water as a dispersion medium. They used MRA binder for developing well-shaped MOF structures, which retained their intrinsic properties after shaping, and evaluated $\mathrm{CO}_{2}$ and $\mathrm{N}_{2}$ adsorption performance, observing a high affinity for $\mathrm{CO}_{2}$ over $\mathrm{N}_{2}$ in all MOF samples tested. In [95], MIL-100(Fe) granules were produced, employing silica sol as an adhesive, to demonstrate MIL-100(Fe) as an adsorbent of high potential for $\mathrm{SF}_{6} / \mathrm{N}_{2}$ separation. The physical and chemical properties of a powder-type MIL- 
100 did not change significantly following the granulation procedure (Fe), except for a small reduction in pore volume. In another study [96], granules of MIL-127(Fe), MIL$100(\mathrm{Fe})$, and $\mathrm{UiO}-66(\mathrm{Zr})$ were produced utilizing $\rho$-alumina as a binder via wet granulation, and their sorption properties were investigated. MIL-127(Fe) depicted a nearly identical uptake behavior after granulation and is noted as a potential candidate for use in gas storage or separation applications. In general, alumina shaping is a promising approach to produce MOFs for applications in gas separation and gas storage; however, this might not apply to all MOF materials. In [97], MIL-101 pellets were shaped with sodium silicate, starch, and water as the adhesive mixture to the MIL-101 powder. The attained paste was extruded by a homemade extruder and then dried. The powder and pellets presented a $\mathrm{CO}_{2}$ uptake capacity of $9.72 \mathrm{mmol} \mathrm{g}^{-1}$ and $6.34 \mathrm{mmol} \mathrm{g}^{-1}$, respectively. In [98], MIL-100(Fe) was formed into granules with silica $(10 \mathrm{wt} \%)$ utilized as a binder and its hydrocarbon separation performance was explored through tests on mixtures of ethane or ethylene with propane. The gases were recovered in high rates (>86\%) with great purities (>94\%) Kusgens et al. reported on the fabrication of $\mathrm{Cu}_{3}(\mathrm{BTC})_{2}$ on monolithic structures through a two-step methodology [99]. The first step included the fabrication of a molding batch, by mixing of $\mathrm{Cu}_{3}(\mathrm{BTC})_{2}$ with Silres MSE 100 (binder) and Culmial MHPC 20,000 P (plasticizer) in a lab-scale kneader. During the second step, a ram extruder was utilized for extruding the molding batch to a monolithic strang. The results showed that the developed monoliths have good mechanical stability and should be considered for gas storage, catalysis, and separation applications. Pereira et al. [100] produced ZIF-8 and MIL-53(Al) pellets by extrusion with alumina as a binder. Various loadings $(5,10$, and $15 \mathrm{wt} \%$ ) of alumina were employed in the composite pellets and this increase resulted in improved mechanical strength, while the shaping process had less of an impact on the ZIF-8 adsorption properties than on the MIL-53(Al). In [101], Thakkar et al. utilized silica (15 wt $\%$ ) as the binding agent in 3D-printed ZIF-7 monoliths. Silica enlarged the pores of the monolithic ZIF-7 and allowed $\mathrm{N}_{2}$ molecules to access the pores of the ZIF-7; as a result, the monolith presented a higher surface area than the pristine powder: $40 \mathrm{~m}^{2} \mathrm{~g}^{-1}$ compared to $16 \mathrm{~m}^{2} \mathrm{~g}^{-1}$. The monolith was tested for its ethane/ethylene adsorption capacities and showed a $85 \% / 87 \%$ uptake performance for $\mathrm{C}_{2} \mathrm{H}_{6} / \mathrm{C}_{2} \mathrm{H}_{4}$ compared to the pristine ZIF-8 powder, and broke at $0.8 \mathrm{MPa}$ in compression tests. In another similar work [102], Thakkar et al. 3D-printed MOF74(Ni) and UTSA-16(Co) structures with bentonite clay (15 and $10 \mathrm{wt} \%$, respectively) as an adhesive and PVA (5 $\mathrm{wt} \%$ ) as a plasticizer, and tested their $\mathrm{CO}_{2}$ adsorption performance. The results revealed that the monoliths' uptake performance was equal to the $79 \%$ and $87 \%$ of their pristine powder form, respectively. Bentonite clay (15 wt $\%)$ as a binder and PVA (5\%) as a plasticizer were also used in a 3D-printing process to develop a MIL101 monolithic structure [103]. The monolith was tested for $\mathrm{CO}_{2}$ removal from enclosed environments. The MIL-101 monolith presented a small surface area decrease of $200 \mathrm{~m}^{2} \mathrm{~g}^{-1}$ and achieved a $75 \% \mathrm{CO}_{2}$ adsorption uptake compared to its powder analogue. In Table 2, a summary of shaped MOFs with inorganic binders is provided.

Table 2. Summary of shaped MOFs with inorganic binders.

\begin{tabular}{|c|c|c|c|c|c|c|}
\hline MOF & Binder (wt $\%)$ & Shape & $\begin{array}{c}\text { S } \\
\text { BET Powder } \\
\left(\mathrm{m}^{2} \mathrm{~g}^{-1}\right)\end{array}$ & $\begin{array}{c}\text { SBET Body } \\
\left(\mathrm{m}^{2} \mathrm{~g}^{-1}\right)\end{array}$ & Application & Reference \\
\hline MIL-100(Fe) & $\rho$-alumina $(5 \%)$ & Sphere & 2088 & 1831 & Ammonia adsorption & [30] \\
\hline MIL-101(Cr) & $\rho$-alumina $(5 \%)$ & Sphere & 4066 & 3685 & $\mathrm{CO}_{2}$ adsorption & [30] \\
\hline UIO-66(Zr) & $\rho$-alumina $(5 \%)$ & Sphere & 1050 & 911 & $\mathrm{CO}_{2}$ adsorption & [30] \\
\hline UIO-66_NH ${ }_{2}$ & $\rho$-alumina ( $5 \%)$ & Sphere & 875 & 823 & $\mathrm{CO}_{2}$ adsorption & [30] \\
\hline ZIF-8 & $\begin{array}{c}\text { Bentonite clay } \\
(10 \%)\end{array}$ & Tablet & 1022.8 & 820.6 & - & [89] \\
\hline ZIF-8 & Alumina $(10 \%)$ & Tablet & 1022.8 & 947.9 & - & [89] \\
\hline ZIF-8 & SB powder $(10 \%)$ & Tablet & 1022.8 & 959.2 & Gas adsorption & [89] \\
\hline ZIF-8 & $\begin{array}{l}\text { Talc powder } \\
(10 \%)\end{array}$ & Tablet & 1022.8 & 951.3 & Gas adsorption & [89] \\
\hline ZIF-8 & $\begin{array}{c}\text { Sesbania powder } \\
(10 \%)\end{array}$ & Tablet & 1022.8 & 846.4 & - & [89] \\
\hline
\end{tabular}


Table 2. Cont.

\begin{tabular}{|c|c|c|c|c|c|c|}
\hline MOF & Binder (wt $\%)$ & Shape & $\begin{array}{l}\text { S BET Powder }_{\text {Bew }} \text { Pow } \\
\quad\left(\mathrm{m}^{2} \mathrm{~g}^{-1}\right)\end{array}$ & $\begin{array}{l}\text { SBET }_{\text {Bedy }} \text { Body } \\
\left(\mathrm{m}^{2} \mathrm{~g}^{-1}\right)\end{array}$ & Application & Reference \\
\hline ZIF-8 & Silica $(10 \%)$ & Tablet & 1022.8 & 945.9 & - & [89] \\
\hline $\mathrm{UiO}-66$ & Graphite (1\%) & Tablet & 1140 & 885 & $\begin{array}{c}\text { Selective adsorption and } \\
\text { separation of xylene isomers } \\
\text { Adsorptive }\end{array}$ & [90] \\
\hline ZIF-8 & Bentonite $(20 \%)$ & Monolith & 1415 & 1083 & $\begin{array}{c}\text { Separations/biobutanol } \\
\text { recovery }\end{array}$ & [91] \\
\hline ZIF-8 & $\begin{array}{c}\text { Bentonite }(16.7 \%) \\
\text { and MC }(16.7 \%)\end{array}$ & Monolith & 1415 & 1070 & $\begin{array}{l}\text { Adsorptive } \\
\text { Separations/biobutanol } \\
\text { recovery }\end{array}$ & [91] \\
\hline HKUST-1 & $\begin{array}{l}\text { Bentonite }(15 \%) \\
\text { and MC }(15 \%)\end{array}$ & Pellet & 1271.2 & 605.1 & MOF shape engineering & [92] \\
\hline ZIF-8 & $\begin{array}{l}\text { Bentonite }(15 \%) \\
\text { and } \mathrm{MC}(15 \%)\end{array}$ & Pellet & 2047 & 1471.5 & MOF shape engineering & [92] \\
\hline ZIF-67 & $\begin{array}{l}\text { Bentonite }(15 \%) \\
\text { and MC }(15 \%)\end{array}$ & Pellet & 1789.6 & 464.4 & MOF shape engineering & [92] \\
\hline $\mathrm{UiO}-66$ & $\begin{array}{l}\text { Bentonite }(15 \%) \\
\text { and MC }(15 \%)\end{array}$ & Pellet & 1110.8 & 187.4 & MOF shape engineering & [92] \\
\hline MIL-101(Cr) & Bentonite $(25 \%)$ & Monolith & - & - & $\mathrm{CO}_{2}$ adsorption & [93] \\
\hline MIL-101 (Cr) & $\begin{array}{l}\text { Bentonite } \\
(25 / 40 \%)\end{array}$ & Monolith & - & - & $\mathrm{CO}_{2}$ adsorption & [94] \\
\hline MIL-100(Fe) & Silica sol $(10 \%)$ & Granule & 1772 & 1619 & $\begin{array}{c}\text { Separation of } \mathrm{SF}_{6} \text { from } \mathrm{SF}_{6} / \mathrm{N}_{2} \\
\text { mixture }\end{array}$ & [95] \\
\hline $\mathrm{UiO}-66(\mathrm{Zr})$ & $\rho$-alumina (5\%) & Bead & 903 & 619 & $\begin{array}{c}\text { Room temperature gas } \\
\text { adsorption } / \mathrm{H}_{2} \mathrm{O} \text { and } \mathrm{CH}_{4} \\
\text { adsorption }\end{array}$ & [96] \\
\hline MIL-100(Fe) & $\rho$-alumina $(5 \%)$ & Bead & 1928 & 1451 & $\begin{array}{c}\text { Room temperature gas } \\
\text { adsorption } / \mathrm{H}_{2} \mathrm{O} \text { and } \mathrm{CH}_{4} \\
\text { adsorption }\end{array}$ & [96] \\
\hline MIL-127(Fe) & $\rho$-alumina $(5 \%)$ & Bead & 1413 & 1266 & $\begin{array}{c}\text { Room temperature gas } \\
\text { adsorption } / \mathrm{H}_{2} \mathrm{O} \text { and } \mathrm{CH}_{4} \\
\text { adsorption }\end{array}$ & [96] \\
\hline MIL-101 & $\begin{array}{l}\text { Sodium silicate } \\
\text { and starch }(7 \%)\end{array}$ & Pellet & 2730 & 1910 & $\mathrm{CO}_{2}$ adsorption & [97] \\
\hline MIL-100(Fe) & Silica $(10 \%)$ & Granule & - & 1568 & $\mathrm{C}_{2} / \mathrm{C}_{3}$ hydrocarbon separation & [98] \\
\hline $\mathrm{Cu}_{3}(\mathrm{BTC})_{2}$ & $\begin{array}{l}\text { Silres MSE } 100 \\
(13.8 \%)\end{array}$ & Monolith & - & 484 & MOF shape engineering & [99] \\
\hline ZIF-8 & $\begin{array}{c}\rho \text {-alumina } \\
(5 / 10 / 15 \%)\end{array}$ & Pellet & - & - & $\mathrm{CH}_{4} / \mathrm{N}_{2}$ separation & [100] \\
\hline MIL-53(Al) & $\begin{array}{l}\rho \text {-alumina } \\
(5 / 10 / 15 \%)\end{array}$ & Pellet & - & - & $\mathrm{CH}_{4} / \mathrm{N}_{2}$ separation & [100] \\
\hline ZIF-7 & Silica $(15 \%)$ & Monolith & 16 & 40 & $\begin{array}{l}\text { Adsorption of ethane and } \\
\text { ethylene }\end{array}$ & [101] \\
\hline MOF-74(Ni) & $\begin{array}{l}\text { Bentonite }(15 \%) \\
\text { and PVA }(5 \%)\end{array}$ & Monolith & 1180 & 737 & Gas adsorption & [102] \\
\hline UTSA-16(Co) & $\begin{array}{l}\text { Bentonite }(10 \%) \\
\text { and PVA }(5 \%)\end{array}$ & Monolith & 727 & 568 & Gas adsorption & {$[102]$} \\
\hline MIL-101 & $\begin{array}{l}\text { Bentonite }(15 \%) \\
\text { and PVA }(5 \%)\end{array}$ & Monolith & 2400 & 2200 & $\begin{array}{c}\mathrm{CO}_{2} \text { removal from enclosed } \\
\text { environments }\end{array}$ & {$[103]$} \\
\hline
\end{tabular}

\subsection{Processes without Binders}

In addition to shaping processes that utilize a binding agent, there are forming procedures that do not require an adhesive. Dhainaut et al. [104] used a tableting instrument to form UiO-66, UiO-67, UiO-66- $\mathrm{NH}_{2}$, and HKUST-1 into tablets without utilizing a binding agent. As observed, with regard to the MOFs of the study, the mechanical stability is proportional to the tablet's bulk density, whereas the latter is disproportional to the surface area. In particular, for a 1.8 to 3.4 -fold increase of the tablet's density, the surface area reduces from 0 up to $30 \%$. Zhang et al. reported on the first high-internal-phase emulsion (HIPE) system developed with a metal-organic framework [28]. They stirred an assembly of MOF HKUST-1 nanocrystals together with a water and oil interface at room temperature and reported a HIPE with good stability suitable for highly porous applications of metal-organic aerogel monoliths. Similarly, Tian et al. reported on the production of four different types of ZIF-8 monoliths (ranging from $1 \mathrm{~mm}^{3}$ to $1 \mathrm{~cm}^{3}$ ), abbreviated as 
ZIF-8HT, ZIF-8LT, ZIF-8LT-HT, and ZIF-8ER, according to the processing method followed, at room temperature and without the use of binders by following a sol-gel process [105]. The resulting monoliths are transparent and maintain both fluorescent capability and ZIF-8 porosity. Tian et al., in a following study [106], extended this approach to develop HKUST-1 binderless monoliths, which achieved an exceptional methane uptake capacity of $259 \mathrm{~cm}^{3}$ (at standard temperatures and pressures (STP)) per $\mathrm{cm}^{3}$ of MOF, reaching the US Department of Energy target [107] of $263 \mathrm{~cm}^{3}$ (STP) $\mathrm{cm}^{-3}$ for methane storage, opening the gate for real-life energy-related applications with regard to absorbed natural gas. Bueken et al. reported on the developments of $\mathrm{Zr}-\mathrm{MOF}$ with a special focus on the presence of water, metal source, and reactant concentration [108]. They developed both monoliths and spheres by following xero gel and oil-drop granulation processes, respectively. The authors suggested that the methodology followed can be applied for further catalysis or adsorption applications and the fabrication of transparent films and coatings.

Purewal et al. reported on the development of MOF- 5 as a hydrogen storage material [109]. They fabricated MOF-5 powder and applied it by pressing it into pellets of various bulk density. The resulting structures were then evaluated with respect to their thermal conductivity, hydrogen adsorption, specific surface area, and crush strength. Tagliabue et al. investigated the fabrication of nickel-based MOF, i.e., CPO-27-Ni, as an adsorbent for gaseous fuels applications [110]. They developed pellets through the application of varied mechanical pressure (0.1-1 GPa) and compared them accordingly with respect to modifications to their crystal structure and methane specific capacity. Majchrzak-Kuceba and Sciubidlo reported on the fabrication of two types of MOF, i.e., CuBTC and MIL-53(Al), and the impact of tabletization, pressure, and time on their carbon dioxide adsorption property. They followed the no-binder pelletizing method by applying a varied pressure (3.7-59.2 $\mathrm{kN} \mathrm{m}^{-2}$ ) for different time-steps (0.5 and $2 \mathrm{~min}$ ) [111]. Interestingly, Lim et al. reported a direct ink writing 3D-printing technique to develop a jelly-like HKUST-1 monolith without any binder, which was then tested for its methane storage capacity [112]. The monolith displayed a surface area of $1134 \mathrm{~m}^{2} \mathrm{~g}^{-1}$ and it retained high levels of crystallinity and porosity, making it a good candidate for energy or gas storage. On the contrary, in another study [113] that also explored the methane storage performance of binderless HKUST-1 macrostructures, it was shown that when HKUST-1 powder was subjected to high compression forces ranging from 0.5 to 5 tons to form wafers, its porosity diminished and its volumetric methane uptake capacity was significantly reduced. A list of MOF structures, formed without the addition of any binder is presented in Table 3.

Table 3. Summary of shaped MOFs without the addition of binders.

\begin{tabular}{|c|c|c|c|c|c|c|}
\hline MOF & Binder & Shape & $\begin{array}{l}\text { S }_{\text {BET Powder }} \text { Powder } \\
\left(\mathrm{m}^{2} \mathrm{~g}^{-1}\right)\end{array}$ & $\begin{array}{l}\mathrm{S}_{\text {BET }} \text { Body } \\
\left(\mathrm{m}^{2} \mathrm{~g}^{-1}\right)\end{array}$ & Application & Reference \\
\hline $\mathrm{Cu}_{3}(\mathrm{BTC})_{2}$ & None & Monolith & 307 & 834 & No application/MOF shape engineering & [28] \\
\hline UiO-66 & None & Tablet & 1426 & 1459 & No application/MOF shape engineering & [104] \\
\hline $\mathrm{UiO}-67$ & None & Tablet & 2034 & 1549 & No application/MOF shape engineering & [104] \\
\hline $\mathrm{UiO}-66-\mathrm{NH}_{2}$ & None & Tablet & 839 & 625 & No application/MOF shape engineering & [104] \\
\hline HKUST-1 & None & Tablet & 1288 & 1091 & No application/MOF shape engineering & [104] \\
\hline ZIF-8HT & None & Monolith & - & 1387 & No application/MOF shape engineering & [105] \\
\hline ZIF-8LT & None & Monolith & - & 1359 & No application/MOF shape engineering & [105] \\
\hline ZIF-8LT-HT & None & Monolith & - & 1423 & No application/MOF shape engineering & [105] \\
\hline ZIF-8ER & None & Monolith & - & 1395 & No application/MOF shape engineering & [105] \\
\hline HKUST-1 & None & Monolith & - & 1193 & Methane adsorption & [106] \\
\hline $\mathrm{UiO}-66$ & None & Sphere & 1167 & 1127 & No application/MOF shape engineering & [108] \\
\hline MOF-5 & None & Pellet & 2762 & 2707 & Hydrogen storage & [109] \\
\hline $\mathrm{CPO}-27-\mathrm{Ni}$ & None & Pellet & - & - & Methane storage & [110] \\
\hline CuBTC & None & Pellet & - & - & $\mathrm{CO}_{2}$ capture & [111] \\
\hline MIL-53(Al) & None & Pellet & - & - & $\mathrm{CO}_{2}$ capture & [111] \\
\hline HKUST-1 & None & monolith & - & 1134 & Methane storage & [112] \\
\hline HKUST-1 & None & tablet & 1850 & - & $\begin{array}{c}\text { Methane storage/MOF shape } \\
\text { engineering }\end{array}$ & [113] \\
\hline
\end{tabular}




\section{Conclusions}

Developing the powdery form of MOF into a monolith is of high importance to various sectors of the industry, as this would make the utilization of MOFs in technical applications much easier. Powders are not suitable for industrial applications, with the most important reasons being obvious: powder is not easy to handle, it is susceptible to abrasion, it blocks or reduces the flow of fluids, and mass loss due to powder blowing is another important issue. Therefore, shaping MOFs into macrostructures would made their utilization in real-life applications viable.

For this purpose, binding agents are widely utilized to develop the powder particles into bigger structures as depicted in Figure 6. Polymer binders (e.g., PVA, PVB, MC) and inorganic binders (e.g., $\rho$-alumina, silica) are two suitable categories of adhesive agents that are used in either pressurized or non-pressurized processes to form a MOF into a pellet, a granule, or a monolith. As noted in other works $[5,8,22,114]$ and also depicted in this study, polymer-type binders have lower weights compared to inorganic binders, which enhances the performance of the structure. These binders are more well-studied and are easier to handle, but on the other hand, there is an increased possibility of pore blockage and reduction of the specific surface area of the MOF, and subsequently, its uptake capacity to gases. However, inorganic binders demonstrate high thermal stability, enhanced mechanical stability, and provide high resistance to abrasion. Therefore, critical information about their behavior and their effects on the MOF structured monoliths will allow for the shaping of even better and more efficient structures. Thus, further research is required to investigate, for example, MOF/binder compatibility, the capabilities of the material after several regeneration cycles, and the improvement of the shaping procedures for reduced loss of MOF powder during the formation process.

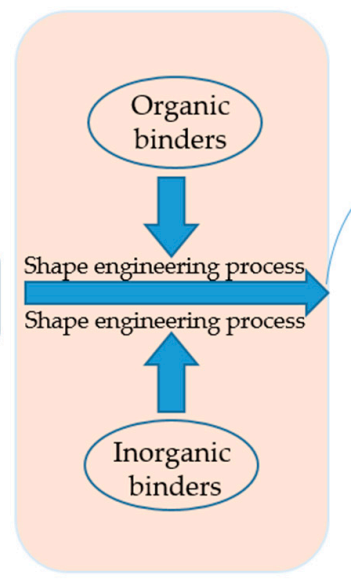

Binders assessed Most popular: PVA

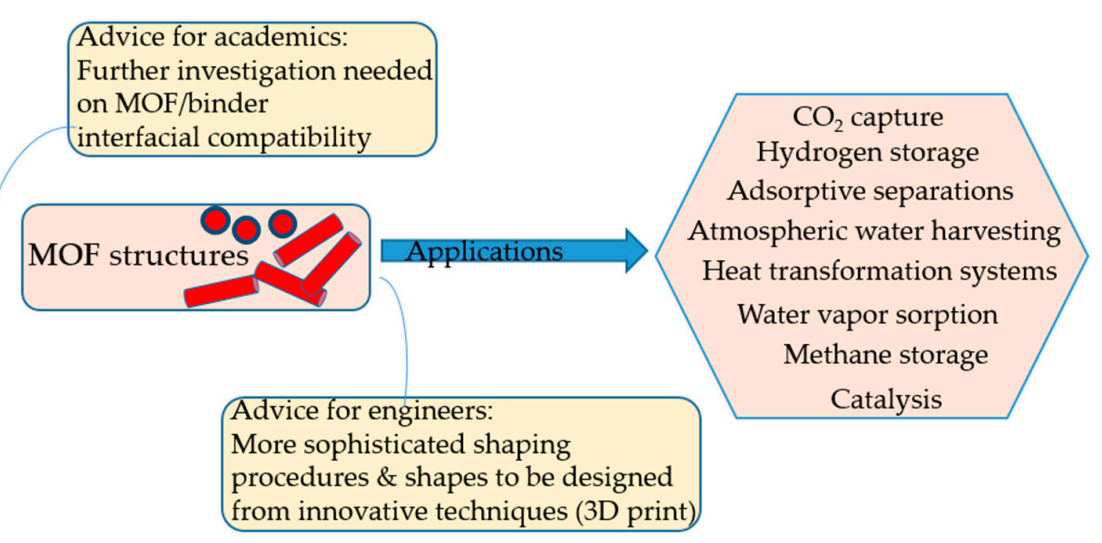

Applications presented Most popular: Gas adsorption

Figure 6. Conclusions scheme.

MOFs are promising nanomaterials for successful applications in various sectors that, until now, the research community has not fully explored. The built environment, for example, is a field that may offer many applications for MOFs, given that they come in a form that is easy to handle. As seen in this review, although scarce, some pioneering applications using MOF shaped bodies try to address issues related to the built environment, such as (i) air purification, (ii) carbon dioxide capture from indoor environments, (iii) increased energy efficiency in water adsorption heat transformation systems as methane adsorbents, (iv) as dehumidifiers, and (v) as natural gas/methane or hydrogen storage agents, which may be a potential application in the future within buildings with regard to energy consumption and storage. Therefore, there are some initial signs that cooling and heating systems, dehumidifiers, filters for air purification, or even decorative indoor ornaments incorporating the porous characteristics of MOFs might gain added value to their functionality and capture 
$\mathrm{CO}_{2}$ or other greenhouse gases, paving the way for real decarbonization of our world. However, for this to be realized, MOFs should be available as rigid macrostructures that maintain their working capacities.

Author Contributions: Conceptualization, V.N.; methodology, V.N.; formal analysis, V.N. and I.K.; investigation, V.N. and I.K.; writing-original draft preparation, V.N. with support from I.K.; review and editing, I.K., M.N.A. and A.L.P.; supervision, M.N.A. and A.L.P. All authors have read and agreed to the published version of the manuscript.

Funding: This research has received funding from the European Union's Horizon 2020 research and innovation programme under the Marie Skłodowska-Curie Grant Agreement No. 765057-SAFERUP! Project.

Institutional Review Board Statement: Not applicable.

Informed Consent Statement: Not applicable.

Data Availability Statement: Not applicable.

Acknowledgments: The authors would like to acknowledge the European Union's Horizon 2020 research and innovation programme under the Marie Skłodowska-Curie Grant Agreement No. 765057 SAFERUP!, website https: / / site.unibo.it/saferup/en (accessed on 25 January 2022).

Conflicts of Interest: The authors declare no conflict of interest.

\section{References}

1. Rabiee, N.; Atarod, M.; Tavakolizadeh, M.; Asgari, S.; Rezaei, M.; Akhavan, O.; Pourjavadi, A.; Jouyandeh, M.; Lima, E.C.; Mashhadzadeh, A.H.; et al. Green metal-organic frameworks (MOFs) for biomedical applications. Microporous Mesoporous Mater. 2022, 111670. [CrossRef]

2. Chen, W.; Zhu, P.; Chen, Y.; Liu, Y.; Du, L.; Wu, C. Iodine Immobilized UiO-66-NH2 Metal-Organic Framework as an Effective Antibacterial Additive for Poly( $\varepsilon$-caprolactone). Polymers 2022, 14, 283. [CrossRef]

3. Gouda, M.; Khalaf, M.M.; Shalabi, K.; Al-Omair, M.A.; El-Lateef, H.M.A. Synthesis and Characterization of Zn-Organic Frameworks Containing Chitosan as a Low-Cost Inhibitor for Sulfuric-Acid-Induced Steel Corrosion: Practical and Computational Exploration. Polymers 2022, 14, 228. [CrossRef]

4. Villajos, J.A. Experimental Volumetric Hydrogen Uptake Determination at $77 \mathrm{~K}$ of Commercially Available Metal-Organic Framework Materials. C 2022, 8, 5. [CrossRef]

5. Valizadeh, B.; Nguyen, T.N.; Stylianou, K.C. Shape engineering of metal-organic frameworks. Polyhedron 2018, 145, 1-15. [CrossRef]

6. Kang, H.; Park, K.H.; Lee, H.-K. Transformation of CuO from Cu-MOF Templates and Their Enhanced Sensing Performance for HCHO: Transformation of CuOs from Cu-MOF Templates. Bull. Korean Chem. Soc. 2016, 37, 123-128. [CrossRef]

7. Lee, J.; Hong, S.; Lee, J.; Kim, S.; Kim, J.; Kim, M. Strategies in Metal-Organic Framework-based Catalysts for the Aerobic Oxidation of Alcohols and Recent Progress. Bull. Korean Chem. Soc. 2021, 42, 359-368. [CrossRef]

8. Ryu, U.; Jee, S.; Rao, P.C.; Shin, J.; Ko, C.; Yoon, M.; Park, K.S.; Choi, K.M. Recent advances in process engineering and upcoming applications of metal-organic frameworks. Coord. Chem. Rev. 2021, 426, 213544. [CrossRef]

9. Seo, H.; Lee, I.; Vadahanambi, S.; Park, H. Metal-Organic Framework Reinforced Acrylic Polymer Marine Coatings. Materials 2022, 15, 27. [CrossRef]

10. Yin, X.; Alsuwaidi, A.; Zhang, X. Hierarchical metal-organic framework (MOF) pore engineering. Microporous Mesoporous Mater. 2022, 330, 111633. [CrossRef]

11. Sriram, G.; Bendre, A.; Mariappan, E.; Altalhi, T.; Kigga, M.; Ching, Y.C.; Jung, H.-Y.; Bhaduri, B.; Kurkuri, M. Recent trends in the application of metal-organic frameworks (MOFs) for the removal of toxic dyes and their removal mechanism-a review. Sustain. Mater. Technol. 2022, 31, e00378. [CrossRef]

12. Ntouros, V.; Kousis, I.; Papadaki, D.; Pisello, A.L.; Assimakopoulos, M.N. Life Cycle Assessment on Different Synthetic Routes of ZIF-8 Nanomaterials. Energies 2021, 14, 4998. [CrossRef]

13. Papaefstathiou, G.S.; Friščić, T.; MacGillivray, L.R. Design and Construction of a 2D Metal Organic Framework with Multiple Cavities: A Nonregular Net with a Paracyclophane that Codes for Multiply Fused Nodes. J. Am. Chem. Soc. 2005, 127, 14160-14161. [CrossRef] [PubMed]

14. Polyakov, V.A.; Butova, V.V.; Erofeeva, E.A.; Tereshchenko, A.A.; Soldatov, A.V. MW Synthesis of ZIF-7. The Effect of Solvent on Particle Size and Hydrogen Sorption Properties. Energies 2020, 13, 6306. [CrossRef]

15. Samanidou, V.F.; Deliyanni, E.A. Metal Organic Frameworks: Synthesis and Application. Molecules 2020, 25, 960. [CrossRef] [PubMed]

16. Al Obeidli, A.; Ben Salah, H.; Al Murisi, M.; Sabouni, R. Recent advancements in MOFs synthesis and their green applications. Int. J. Hydrogen Energy 2022, 47, 2561-2593. [CrossRef] 
17. Valizadeh, B.; Nguyen, T.N.; Smit, B.; Stylianou, K.C. Porous Metal-Organic Framework@Polymer Beads for Iodine Capture and Recovery Using a Gas-Sparged Column. Adv. Funct. Mater. 2018, 28, 1801596. [CrossRef]

18. Al-Rowaili, F.N.; Zahid, U.; Onaizi, S.; Khaled, M.; Jamal, A.; AL-Mutairi, E.M. A review for Metal-Organic Frameworks (MOFs) utilization in capture and conversion of carbon dioxide into valuable products. J. CO2 Util. 2021, 53, 101715. [CrossRef]

19. Hou, J.; Sapnik, A.F.; Bennett, T.D. Metal-organic framework gels and monoliths. Chem. Sci. 2020, 11, 310-323. [CrossRef] [PubMed]

20. Stanley, P.M.; Warnan, J. Molecular Dye-Sensitized Photocatalysis with Metal-Organic Framework and Metal Oxide Colloids for Fuel Production. Energies 2021, 14, 4260. [CrossRef]

21. Samantaray, S.S.; Putnam, S.T.; Stadie, N.P. Volumetrics of Hydrogen Storage by Physical Adsorption. Inorganics 2021, 9 , 45. [CrossRef]

22. Yeskendir, B.; Dacquin, J.-P.; Lorgouilloux, Y.; Courtois, C.; Royer, S.; Dhainaut, J. From metal-organic framework powders to shaped solids: Recent developments and challenges. Mater. Adv. 2021, 2, 7139-7186. [CrossRef]

23. Shah, B.B.; Kundu, T.; Zhao, D. Mechanical Properties of Shaped Metal-Organic Frameworks. Top. Curr. Chem. Cham 2019, 377, 25. [CrossRef]

24. Lorignon, F.; Gossard, A.; Carboni, M. Hierarchically porous monolithic MOFs: An ongoing challenge for industrial-scale effluent treatment. Chem. Eng. J. 2020, 393, 124765. [CrossRef]

25. Aguilera-Sigalat, J.; Bradshaw, D. A colloidal water-stable MOF as a broad-range fluorescent $\mathrm{pH}$ sensor via post-synthetic modification. Chem. Commun. 2014, 50, 4711-4713. [CrossRef]

26. Wu, J.; Dai, Q.; Zhang, H.; Li, X. A defect-free MOF composite membrane prepared via in-situ binder-controlled restrained second-growth method for energy storage device. Energy Storage Mater. 2021, 35, 687-694. [CrossRef]

27. Zheng, J.; Cui, X.; Yang, Q.; Ren, Q.; Yang, Y.; Xing, H. Shaping of ultrahigh-loading MOF pellet with a strongly anti-tearing binder for gas separation and storage. Chem. Eng. J. 2018, 354, 1075-1082. [CrossRef]

28. Zhang, B.; Zhang, J.; Liu, C.; Peng, L.; Sang, X.; Han, B.; Ma, X.; Luo, T.; Tan, X.; Yang, G. High-internal-phase emulsions stabilized by metal-organic frameworks and derivation of ultralight metal-organic aerogels. Sci. Rep. 2016, 6, 21401. [CrossRef]

29. Cousin-Saint-Remi, J.; Finoulst, A.-L.; Jabbour, C.; Baron, G.V.; Denayer, J.F.M. Selection of binder recipes for the formulation of MOFs into resistant pellets for molecular separations by fixed-bed adsorption. Microporous Mesoporous Mater. 2020, 304 , 109322. [CrossRef]

30. Valekar, A.H.; Cho, K.-H.; Lee, U.-H.; Lee, J.S.; Yoon, J.W.; Hwang, Y.K.; Lee, S.G.; Cho, S.J.; Chang, J.-S. Shaping of porous metal-organic framework granules using mesoporous $\rho$-alumina as a binder. RSC Adv. 2017, 7, 55767-55777. [CrossRef]

31. Khabzina, Y.; Dhainaut, J.; Ahlhelm, M.; Richter, H.-J.; Reinsch, H.; Stock, N.; Farrusseng, D. Synthesis and Shaping Scale-up Study of Functionalized UiO-66 MOF for Ammonia Air Purification Filters. Ind. Eng. Chem. Res. 2018, 57, 8200-8208. [CrossRef]

32. Lee, U.-H.; Valekar, A.H.; Hwang, Y.K.; Chang, J.-S. Granulation and Shaping of Metal-Organic Frameworks. In The Chemistry of Metal-Organic Frameworks, 1st ed.; Kaskel, S., Ed.; Wiley-VCH: Weinheim, Germany, 2016; pp. 551-572.

33. Liu, D.; Purewal, J.J.; Yang, J.; Sudik, A.; Maurer, S.; Mueller, U.; Ni, J.; Siegel, D.J. MOF-5 composites exhibiting improved thermal conductivity. Int. J. Hydrogen Energy 2012, 37, 6109-6117. [CrossRef]

34. Li, H.; Eddaoudi, M.; O'Keeffe, M.; Yaghi, O.M. Design and synthesis of an exceptionally stable and highly porous metal-organic framework. Nature 1999, 402, 276-279. [CrossRef]

35. Furukawa, H.; Cordova, K.E.; O'Keeffe, M.; Yaghi, O.M. The Chemistry and Applications of Metal-Organic Frameworks. Science 2013, 341, 1230444. [CrossRef]

36. Ogawa, T.; Iyoki, K.; Fukushima, T.; Kajikawa, Y. Landscape of Research Areas for Zeolites and Metal-Organic Frameworks Using Computational Classification Based on Citation Networks. Materials 2017, 10, 1428. [CrossRef]

37. Govender, S.; Friedrich, H.B. Monoliths: A Review of the Basics, Preparation Methods and Their Relevance to Oxidation. Catalysts 2017, 7, 62. [CrossRef]

38. Free, Z.; Hernandez, M.; Mashal, M.; Mondal, K. A Review on Advanced Manufacturing for Hydrogen Storage Applications. Energies 2021, 14, 8513. [CrossRef]

39. Mahmoud, E.; Ali, L.; El Sayah, A.; Alkhatib, S.A.; Abdulsalam, H.; Juma, M.; Al-Muhtaseb, A.H. Implementing Metal-Organic Frameworks for Natural Gas Storage. Crystals 2019, 9, 406. [CrossRef]

40. Connolly, B.M.; Madden, D.G.; Wheatley, A.E.H.; Fairen-Jimenez, D. Shaping the Future of Fuel: Monolithic Metal-Organic Frameworks for High-Density Gas Storage. J. Am. Chem. Soc. 2020, 142, 8541-8549. [CrossRef]

41. Goodman, L.A. Snowball Sampling. Ann. Math. Stat. 1961, 32, 148-170. [CrossRef]

42. Van Eck, N.J.; Waltman, L. Software survey: VOSviewer, a computer program for bibliometric mapping. Scientometrics 2010, 84, 523-538. [CrossRef]

43. Manni, M.; Nicolini, A. Multi-Objective Optimization Models to Design a Responsive Built Environment: A Synthetic Review. Energies 2022, 15, 486. [CrossRef]

44. Kalaj, M.; Bentz, K.C.; Ayala, S.; Palomba, J.M.; Barcus, K.S.; Katayama, Y.; Cohen, S.M. MOF-Polymer Hybrid Materials: From Simple Composites to Tailored Architectures. Chem. Rev. 2020, 120, 8267-8302. [CrossRef]

45. Boussemghoune, M.; Chikhi, M.; Ozay, Y.; Guler, P.; Ozbey Unal, B.; Dizge, N. The Investigation of Organic Binder Effect on Morphological Structure of Ceramic Membrane Support. Symmetry 2020, 12, 770. [CrossRef] 
46. National Center for Biotechnology Information. PubChem Compound Summary for CID 11199, Polyvinyl Alcohol. 2022. Available online: https:/ / pubchem.ncbi.nlm.nih.gov/compound/11199 (accessed on 11 February 2022).

47. Olabisi, O.; Adewale, K. (Eds.) Handbook of Thermoplastics, 2nd ed.; Plastics Engineering; CRC Press: Boca Raton, FL, USA, 2015; ISBN 978-1-4665-7722-0.

48. PVB | 63148-65-2. Available online: https://www.chemicalbook.com/ChemicalProductProperty_EN_CB0720498.htm (accessed on 11 February 2022).

49. Ida, S. PES (Poly(ether sulfone)), Polysulfone. In Encyclopedia of Polymeric Nanomaterials; Kobayashi, S., Müllen, K., Eds.; Springer: Berlin/Heidelberg, Germany, 2021; pp. 1-8. ISBN 978-3-642-36199-9.

50. Fluorinated Coatings and Finishes Handbook-2nd Edition. Available online: https://www.elsevier.com/books/fluorinatedcoatings-and-finishes-handbook/mckeen/978-0-323-37126-1 (accessed on 13 February 2022).

51. Poly(vinylpyrrolidone). CAS Common Chemistry. CAS, a Division of the American Chemical Society, n.d. Available online: https:/ / commonchemistry.cas.org/detail?cas_rn=9003-39-8 (accessed on 13 February 2022).

52. Methyl Cellulose | 9004-67-5. Available online: https://www.chemicalbook.com/ChemicalProductProperty_EN_CB3474718.htm (accessed on 13 February 2022).

53. Hydroxypropyl Cellulose | 9004-64-2. Available online: https://www.chemicalbook.com/ChemicalProductProperty_EN_CB024 1870.htm (accessed on 13 February 2022).

54. Gaikwad, S.; Kim, Y.; Gaikwad, R.; Han, S. Enhanced $\mathrm{CO}_{2}$ capture capacity of amine-functionalized MOF-177 metal organic framework. J. Environ. Chem. Eng. 2021, 9, 105523. [CrossRef]

55. Taddei, M.; McPherson, M.J.; Gougsa, A.; Lam, J.; Sewell, J.; Andreoli, E. An Optimised Compaction Process for Zr-Fumarate (MOF-801). Inorganics 2019, 7, 110. [CrossRef]

56. Ren, J.; Musyoka, N.M.; Langmi, H.W.; Swartbooi, A.; North, B.C.; Mathe, M. A more efficient way to shape metal-organic framework (MOF) powder materials for hydrogen storage applications. Int. J. Hydrogen Energy 2015, 40, 4617-4622. [CrossRef]

57. Chanut, N.; Wiersum, A.D.; Lee, U.-H.; Hwang, Y.K.; Ragon, F.; Chevreau, H.; Bourrelly, S.; Kuchta, B.; Chang, J.-S.; Serre, C.; et al . Observing the Effects of Shaping on Gas Adsorption in Metal-Organic Frameworks. Eur. J. Inorg. Chem. 2016, 2016, 4416-4423. [CrossRef]

58. Hindocha, S.; Poulston, S. Study of the scale-up, formulation, ageing and ammonia adsorption capacity of MIL-100(Fe), Cu-BTC and CPO-27(Ni) for use in respiratory protection filters. Faraday Discuss. 2017, 201, 113-125. [CrossRef]

59. Cousin-Saint-Remi, J.; Van der Perre, S.; Segato, T.; Delplancke, M.-P.; Goderis, S.; Terryn, H.; Baron, G.; Denayer, J. Highly Robust MOF Polymeric Beads with a Controllable Size for Molecular Separations. ACS Appl. Mater. Interfaces 2019, 11, 13694-13703. [CrossRef]

60. Abbasi, Z.; Shamsaei, E.; Fang, X.-Y.; Ladewig, B.; Wang, H. Simple fabrication of zeolitic imidazolate framework ZIF-8/polymer composite beads by phase inversion method for efficient oil sorption. J. Colloid Interface Sci. 2017, 493, 150-161. [CrossRef] [PubMed]

61. Hastürk, E.; Höfert, S.-P.; Topalli, B.; Schlüsener, C.; Janiak, C. Shaping of MOFs via freeze-casting method with hydrophilic polymers and their effect on textural properties. Microporous Mesoporous Mater. 2020, 295, 109907. [CrossRef]

62. Kim, J.; Kim, S.-H.; Yang, S.-T.; Ahn, W.-S. Bench-scale preparation of Cu3(BTC)2 by ethanol reflux: Synthesis optimization and adsorption/catalytic applications. Microporous Mesoporous Mater. 2012, 161, 48-55. [CrossRef]

63. Finsy, V.; Ma, L.; Alaerts, L.; De Vos, D.E.; Baron, G.V.; Denayer, J.F.M. Separation of CO2/CH4 mixtures with the MIL-53(Al) metal-organic framework. Microporous Mesoporous Mater. 2009, 120, 221-227. [CrossRef]

64. Zhu, H.; Zhang, Q.; Zhu, S. Assembly of a Metal-Organic Framework into 3 D Hierarchical Porous Monoliths Using a Pickering High Internal Phase Emulsion Template. Chem.-Eur. J. 2016, 22, 8751-8755. [CrossRef]

65. Grande, C.A.; Águeda, V.I.; Spjelkavik, A.; Blom, R. An efficient recipe for formulation of metal-organic Frameworks. Chem. Eng. Sci. 2015, 124, 154-158. [CrossRef]

66. Agueda, V.I.; Delgado, J.A.; Uguina, M.A.; Brea, P.; Spjelkavik, A.I.; Blom, R.; Grande, C. Adsorption and diffusion of $\mathrm{H}_{2}$, $\mathrm{N}_{2}$, $\mathrm{CO}$, $\mathrm{CH}_{4}$ and $\mathrm{CO}_{2}$ in UTSA-16 metal-organic framework extrudates. Chem. Eng. Sci. 2015, 124, 159-169. [CrossRef]

67. Hastürk, E.; Schlüsener, C.; Quodbach, J.; Schmitz, A.; Janiak, C. Shaping of metal-organic frameworks into mechanically stable monoliths with poly(vinyl alcohol) by phase separation technique. Microporous Mesoporous Mater. 2019, 280, 277-287. [CrossRef]

68. Edubilli, S.; Gumma, S. A systematic evaluation of UiO-66 metal organic framework for $\mathrm{CO}_{2} / \mathrm{N}_{2}$ separation. Sep. Purif. Technol. 2019, 224, 85-94. [CrossRef]

69. Solovyeva, M.V.; Gordeeva, L.G.; Aristov, Y.I. “MIL-101(Cr)-methanol” as working pair for adsorption heat transformation cycles: Adsorbent shaping, adsorption equilibrium and dynamics. Energy Convers. Manag. 2019, 182, 299-306. [CrossRef]

70. Delgado, J.A.; Águeda, V.I.; Uguina, M.A.; Brea, P.; Grande, C.A. Comparison and evaluation of agglomerated MOFs in biohydrogen purification by means of pressure swing adsorption (PSA). Chem. Eng. J. 2017, 326, 117-129. [CrossRef]

71. Gökpinar, S.; Ernst, S.-J.; Hastürk, E.; Möllers, M.; El Aita, I.; Wiedey, R.; Tannert, N.; Nießing, S.; Abdpour, S.; Schmitz, A.; et al. Air-Con Metal-Organic Frameworks in Binder Composites for Water Adsorption Heat Transformation Systems. Ind. Eng. Chem. Res. 2019, 58, 21493-21503. [CrossRef]

72. Lorignon, F.; Gossard, A.; Carboni, M.; Meyer, D. From wastes to interconnected porous monolith: Upcycling of Al-based metal organic framework via pickering emulsion template. Mater. Lett. 2021, 296, 129931. [CrossRef] 
73. Kreider, M.C.; Sefa, M.; Fedchak, J.A.; Scherschligt, J.; Bible, M.; Natarajan, B.; Klimov, N.N.; Miller, A.E.; Ahmed, Z.; Hartings, M.R. Toward 3D printed hydrogen storage materials made with ABS-MOF composites. Polym. Adv. Technol. 2018, 29, 867-873. [CrossRef] [PubMed]

74. Hiraide, S.; Arima, H.; Tanaka, H.; Miyahara, M.T. Slacking of Gate Adsorption Behavior on Metal-Organic Frameworks under an External Force. ACS Appl. Mater. Interfaces 2021, 13, 30213-30223. [CrossRef] [PubMed]

75. Maher, H.; Rupam, T.H.; Rocky, K.A.; Bassiouny, R.; Saha, B.B. Silica gel-MIL 100(Fe) composite adsorbents for ultra-low heat-driven atmospheric water harvester. Energy 2022, 238, 121741. [CrossRef]

76. Park, J.; Chae, Y.S.; Kang, D.W.; Kang, M.; Choe, J.H.; Kim, S.; Kim, J.Y.; Jeong, Y.W.; Hong, C.S. Shaping of a Metal-Organic Framework-Polymer Composite and Its CO2 Adsorption Performances from Humid Indoor Air. ACS Appl. Mater. Interfaces 2021, 13, 25421-25427. [CrossRef]

77. Munusamy, K.; Sethia, G.; Patil, D.V.; Somayajulu Rallapalli, P.B.; Somani, R.S.; Bajaj, H.C. Sorption of carbon dioxide, methane, nitrogen and carbon monoxide on MIL-101(Cr): Volumetric measurements and dynamic adsorption studies. Chem. Eng. J. 2012, 195-196, 359-368. [CrossRef]

78. Kriesten, M.; Vargas Schmitz, J.; Siegel, J.; Smith, C.E.; Kaspereit, M.; Hartmann, M. Shaping of Flexible Metal-Organic Frameworks: Combining Macroscopic Stability and Framework Flexibility. Eur. J. Inorg. Chem. 2019, 2019, 4700-4709. [CrossRef]

79. Regufe, M.J.; Tamajon, J.; Ribeiro, A.M.; Ferreira, A.; Lee, U.-H.; Hwang, Y.K.; Chang, J.-S.; Serre, C.; Loureiro, J.M.; Rodrigues, A.E. Syngas Purification by Porous Amino-Functionalized Titanium Terephthalate MIL-125. Energy Fuels 2015, $29,4654-4664$. [CrossRef]

80. Wu, K.; Guo, L.; Zhang, Z.; Yang, Q.; Yang, Y.; Ren, Q.; Bao, Z. Shaping of gallate-based metal-organic frameworks for adsorption separation of ethylene from acetylene and ethane. J. Colloid Interface Sci. 2021, 581, 177-184. [CrossRef] [PubMed]

81. Ohsaki, S.; Nakahara, Y.; Nakamura, H.; Watano, S. Flowability improvement of soft metal-organic framework particles by wet granulation. Microporous Mesoporous Mater. 2020, 293, 109785. [CrossRef]

82. Lv, D.; Chen, J.; Yang, K.; Wu, H.; Chen, Y.; Duan, C.; Wu, Y.; Xiao, J.; Xi, H.; Li, Z.; et al. Ultrahigh $\mathrm{CO}_{2} / \mathrm{CH}_{4}$ and $\mathrm{CO}_{2} / \mathrm{N}_{2}$ adsorption selectivities on a cost-effectively L-aspartic acid based metal-organic framework. Chem. Eng. J. 2019, 375, 122074. [CrossRef]

83. Wickenheisser, M.; Herbst, A.; Tannert, R.; Milow, B.; Janiak, C. Hierarchical MOF-xerogel monolith composites from embedding MIL-100(Fe,Cr) and MIL-101(Cr) in resorcinol-formaldehyde xerogels for water adsorption applications. Microporous Mesoporous Mater. 2015, 215, 143-153. [CrossRef]

84. Bazer-Bachi, D.; Assié, L.; Lecocq, V.; Harbuzaru, B.; Falk, V. Towards industrial use of metal-organic framework: Impact of shaping on the MOF properties. Powder Technol. 2014, 255, 52-59. [CrossRef]

85. ICSC 0384-BENTONITE. Available online: https://inchem.org/documents/icsc/icsc/eics0384.htm (accessed on 14 February 2022)

86. National Center for Biotechnology Information. PubChem Compound Summary for CID 24261, Silicon Dioxide. 2022. Available online: https:// pubchem.ncbi.nlm.nih.gov/compound/24261 (accessed on 14 February 2022).

87. Xie, Y.; Kocaefe, D.; Kocaefe, Y.; Cheng, J.; Liu, W. The Effect of Novel Synthetic Methods and Parameters Control on Morphology of Nano-alumina Particles. Nanoscale Res. Lett. 2016, 11, 259. [CrossRef]

88. National Center for Biotechnology Information. PubChem Compound Summary for CID 9989226, Aluminum Oxide. 2022. Available online: https:/ / pubchem.ncbi.nlm.nih.gov/compound/9989226 (accessed on 14 February 2022).

89. Zhu, J.; Jiang, L.; Dai, C.; Yang, N.; Lei, Z. Gas adsorption in shaped zeolitic imidazolate framework-8. Chin. J. Chem. Eng. 2015, 23, 1275-1282. [CrossRef]

90. Moreira, M.A.; Santos, J.C.; Ferreira, A.F.P.; Loureiro, J.M.; Ragon, F.; Horcajada, P.; Shim, K.-E.; Hwang, Y.-K.; Lee, U.-H.; Chang, J.-S.; et al. Reverse Shape Selectivity in the Liquid-Phase Adsorption of Xylene Isomers in Zirconium Terephthalate MOF UiO-66. Langmuir 2012, 28, 5715-5723. [CrossRef]

91. Lefevere, J.; Claessens, B.; Mullens, S.; Baron, G.; Cousin-Saint-Remi, J.; Denayer, J.F.M. 3D-Printed Zeolitic Imidazolate Framework Structures for Adsorptive Separations. ACS Appl. Nano Mater. 2019, 2, 4991-4999. [CrossRef]

92. Tsalaporta, E.; MacElroy, J.M.D. A comparative study of the physical and chemical properties of pelletized HKUST-1, ZIF-8, ZIF-67 and UiO-66 powders. Heliyon 2020, 6, e04883. [CrossRef]

93. Hong, W.Y.; Perera, S.P.; Burrows, A.D. Comparison of MIL-101(Cr) metal-organic framework and $13 \mathrm{X}$ zeolite monoliths for $\mathrm{CO}_{2}$ capture. Microporous Mesoporous Mater. 2020, 308, 110525. [CrossRef]

94. Hong, W.Y.; Perera, S.P.; Burrows, A.D. Manufacturing of metal-organic framework monoliths and their application in $\mathrm{CO}_{2}$ adsorption. Microporous Mesoporous Mater. 2015, 214, 149-155. [CrossRef]

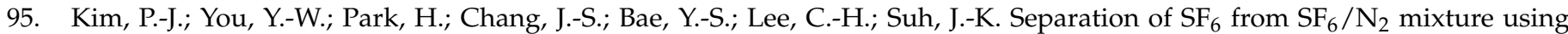
metal-organic framework MIL-100(Fe) granule. Chem. Eng. J. 2015, 262, 683-690. [CrossRef]

96. Iacomi, P.; Lee, U.-H.; Valekar, A.H.; Chang, J.-S.; Llewellyn, P.L. Investigating the effect of alumina shaping on the sorption properties of promising metal-organic frameworks. RSC Adv. 2019, 9, 7128-7135. [CrossRef]

97. Montazerolghaem, M.; Aghamiri, S.F.; Talaie, M.R.; Tangestaninejad, S. A comparative investigation of $\mathrm{CO}_{2}$ adsorption on powder and pellet forms of MIL-101. J. Taiwan Inst. Chem. Eng. 2017, 72, 45-52. [CrossRef]

98. Martins, V.F.D.; Seabra, R.; Silva, P.; Ribeiro, A.M.; Cho, K.H.; Lee, U.-H.; Chang, J.-S.; Loureiro, J.M.; Rodrigues, A.E.; Ferreira, A. $C_{2} / C_{2}$ Hydrocarbon Separation by Pressure Swing Adsorption on MIL-100(Fe). Ind. Eng. Chem. Res. 2020, 59, 10568-10582. [CrossRef] 
99. Küsgens, P.; Zgaverdea, A.; Fritz, H.-G.; Siegle, S.; Kaskel, S. Metal-Organic Frameworks in Monolithic Structures. J. Am. Ceram. Soc. 2010, 93, 2476-2479. [CrossRef]

100. Pereira, A.; Ferreira, A.F.P.; Rodrigues, A.; Ribeiro, A.M.; Regufe, M.J. Shaping of ZIF-8 and MIL-53(Al) adsorbents for $\mathrm{CH}_{4} / \mathrm{N}_{2}$ separation. Microporous Mesoporous Mater. 2022, 331, 111648. [CrossRef]

101. Thakkar, H.; Al-Naddaf, Q.; Legion, N.; Hovis, M.; Krishnamurthy, A.; Rownaghi, A.A.; Rezaei, F. Adsorption of Ethane and Ethylene over 3D-Printed Ethane-Selective Monoliths. ACS Sustain. Chem. Eng. 2018, 6, 15228-15237. [CrossRef]

102. Thakkar, H.; Eastman, S.; Al-Naddaf, Q.; Rownaghi, A.A.; Rezaei, F. 3D-Printed Metal-Organic Framework Monoliths for Gas Adsorption Processes. ACS Appl. Mater. Interfaces 2017, 9, 35908-35916. [CrossRef]

103. Lawson, S.; Griffin, C.; Rapp, K.; Rownaghi, A.A.; Rezaei, F. Amine-Functionalized MIL-101 Monoliths for $\mathrm{CO}_{2}$ Removal from Enclosed Environments. Energy Fuels 2019, 33, 2399-2407. [CrossRef]

104. Dhainaut, J.; Avci-Camur, C.; Troyano, J.; Legrand, A.; Canivet, J.; Imaz, I.; Maspoch, D.; Reinsch, H.; Farrusseng, D. Systematic study of the impact of MOF densification into tablets on textural and mechanical properties. CrystEngComm 2017, 19, 4211-4218. [CrossRef]

105. Tian, T.; Velazquez-Garcia, J.; Bennett, T.D.; Fairen-Jimenez, D. Mechanically and chemically robust ZIF-8 monoliths with high volumetric adsorption capacity. J. Mater. Chem. A 2015, 3, 2999-3005. [CrossRef]

106. Tian, T.; Zeng, Z.; Vulpe, D.; Casco, M.E.; Divitini, G.; Midgley, P.A.; Silvestre-Albero, J.; Tan, J.-C.; Moghadam, P.Z.; FairenJimenez, D. A sol-gel monolithic metal-organic framework with enhanced methane uptake. Nat. Mater. 2018, 17, 174-179. [CrossRef] [PubMed]

107. Gallagher, J. Towards methane targets. Nat. Energy 2018, 3, 86. [CrossRef]

108. Bueken, B.; Velthoven, N.V.; Willhammar, T.; Stassin, T.; Stassen, I.; Keen, D.A.; Baron, G.V.; Denayer, J.F.M.; Ameloot, R.; Bals, S.; et al. Gel-based morphological design of zirconium metal-organic frameworks. Chem. Sci. 2017, 8, 3939-3948. [CrossRef]

109. Purewal, J.J.; Liu, D.; Yang, J.; Sudik, A.; Siegel, D.J.; Maurer, S.; Müller, U. Increased volumetric hydrogen uptake of MOF-5 by powder densification. Int. J. Hydrogen Energy 2012, 37, 2723-2727. [CrossRef]

110. Tagliabue, M.; Rizzo, C.; Millini, R.; Dietzel, P.D.C.; Blom, R.; Zanardi, S. Methane storage on CPO-27-Ni pellets. J. Porous Mater. 2011, 18, 289-296. [CrossRef]

111. Majchrzak-Kucęba, I.; Ściubidło, A. Shaping metal-organic framework (MOF) powder materials for CO2 capture applications-A thermogravimetric study. J. Therm. Anal. Calorim. 2019, 138, 4139-4144. [CrossRef]

112. Lim, G.J.H.; Wu, Y.; Shah, B.B.; Koh, J.J.; Liu, C.K.; Zhao, D.; Cheetham, A.K.; Wang, J.; Ding, J. 3D-Printing of Pure Metal-Organic Framework Monoliths. ACS Mater. Lett. 2019, 1, 147-153. [CrossRef]

113. Peng, Y.; Krungleviciute, V.; Eryazici, I.; Hupp, J.T.; Farha, O.K.; Yildirim, T. Methane Storage in Metal-Organic Frameworks: Current Records, Surprise Findings, and Challenges. J. Am. Chem. Soc. 2013, 135, 11887-11894. [CrossRef] [PubMed]

114. Liu, X.-M.; Xie, L.-H.; Wu, Y. Recent advances in the shaping of metal-organic frameworks. Inorg. Chem. Front. 2020, 7, 2840-2866. [CrossRef] 